\title{
Fate of Fissile Material Bound to Monosodium Titanate (MST) During Copper Catalyzed Peroxide Oxidation (CCPO) of Tank 48H Waste
}

K. M. L. Taylor-Pashow

August 2012

Savannah River National Laboratory

Savannah River Nuclear Solutions, LLC Aiken, SC 29808

Prepared for the U.S. Department of Energy under contract number DE-AC09-08SR22470. 
SRNL-STI-2012-00391

Revision 0

\section{DISCLAIMER}

This work was prepared under an agreement with and funded by the U.S. Government. Neither the U.S. Government or its employees, nor any of its contractors, subcontractors or their employees, makes any express or implied:

1. warranty or assumes any legal liability for the accuracy, completeness, or for the use or results of such use of any information, product, or process disclosed; or

2. representation that such use or results of such use would not infringe privately owned rights; or

3. endorsement or recommendation of any specifically identified commercial product, process, or service.

Any views and opinions of authors expressed in this work do not necessarily state or reflect those of the United States Government, or its contractors, or subcontractors.

\section{Printed in the United States of America \\ Prepared for \\ U.S. Department of Energy}


Keywords: $M S T$, CCPO, Tank $48 \mathrm{H}$, fissile

Retention: Permanent

\section{Fate of Fissile Material Bound to Monosodium Titanate (MST) During Copper Catalyzed Peroxide Oxidation (CCPO) of Tank 48H Waste}

K. M. L. Taylor-Pashow

August 2012

Savannah River National Laboratory

Savannah River Nuclear Solutions, LLC Aiken, SC 29808

Prepared for the U.S. Department of Energy under contract number DE-AC09-08SR22470. 


\section{REVIEWS AND APPROVALS}

AUTHORS:

K. M. L. Taylor-Pashow, Separations and Actinide Science Programs

Date

TECHNICAL REVIEW:

T. B. Peters, Separations and Actinide Science Programs

Date

APPROVAL:

S. D. Fink, Manager

Date

Separations and Actinide Science Programs

S. L. Marra, Manager

Date

Environmental \& Chemical Process Technology Research Programs

K. H. Subramanian, Manager

Date

SRR Engineering 


\section{ACKNOWLEDGEMENTS}

The author acknowledges David Hobbs for helpful discussions and input regarding the actinide chemistry and MST behavior observed during this work. 


\section{EXECUTIVE SUMMARY}

At the Savannah River Site (SRS), Tank 48H currently holds approximately 240,000 gallons of slurry which contains potassium and cesium tetraphenylborate (TPB). A copper catalyzed peroxide oxidation (CCPO) reaction is currently being examined as a method for destroying the TPB present in Tank 48H. Part of the development of that process includes an examination of the fate of the Tank $48 \mathrm{H}$ fissile material which is adsorbed onto monosodium titanate (MST) particles. This report details results from experiments designed to examine the potential degradation of MST during CCPO processing and the subsequent fate of the adsorbed fissile material.

Experiments were conducted to simulate the CCPO process on MST solids loaded with sorbates in a simplified Tank $48 \mathrm{H}$ simulant. Loaded MST solids were placed into the Tank $48 \mathrm{H}$ simplified simulant without TPB, and the experiments were then carried through acid addition ( $\mathrm{pH}$ adjustment to 11$)$, peroxide addition, holding at temperature $\left(50{ }^{\circ} \mathrm{C}\right)$ for one week, and finally $\mathrm{NaOH}$ addition to bring the free hydroxide concentration to a target concentration of $1 \mathrm{M}$. Testing was conducted without TPB to show the maximum possible impact on MST since the competing oxidation of TPB with peroxide was absent. In addition, the $\mathrm{Cu}$ catalyst was also omitted, which will maximize the interaction of $\mathrm{H}_{2} \mathrm{O}_{2}$ with the MST; however, the results may be non-conservative assuming the $\mathrm{Cu}$-peroxide active intermediate is more reactive than the peroxide radical itself.

The study found that both $\mathrm{U}$ and Pu desorb from the MST when the peroxide addition begins, although to different extents. Virtually all of the U goes into solution at the beginning of the peroxide addition, whereas $\mathrm{Pu}$ reaches a maximum of $\sim 34 \%$ leached during the peroxide addition. Ti from the MST was also found to come into solution during the peroxide addition. Therefore, $\mathrm{Ti}$ is present with the fissile in solution.

After the peroxide addition is complete, the $\mathrm{Pu}$ and $\mathrm{Ti}$ are found to precipitate from solution, while the $\mathrm{U}$ remains in solution throughout the remaining processes, including $\mathrm{pH}$ adjustment to $1 \mathrm{M}$ free hydroxide. The Ti is likely forming a peroxotitanate material, which can then resorb the leached $\mathrm{Pu}$ from solution, but has a low affinity for U. Since Pu was not detected in the SEMEDS studies, it cannot be conclusively determined in what form the Pu returns to the solids; however, the Pu likely resorbed onto the peroxotitanate material.

Based on the results of this experiment, Savannah River National Laboratory (SRNL) recommends the following experiments to further examine the fate of fissile material in CCPO processing of Tank $48 \mathrm{H}$.

- Repeat with full simulant matrix (organic and $\mathrm{Cu}$ catalyst present along with simulated radioactive sludge).

- Repeat of the above test after selection of final conditions (i.e., $\mathrm{pH}$, temperature) if they differ from conditions tested. 


\section{TABLE OF CONTENTS}

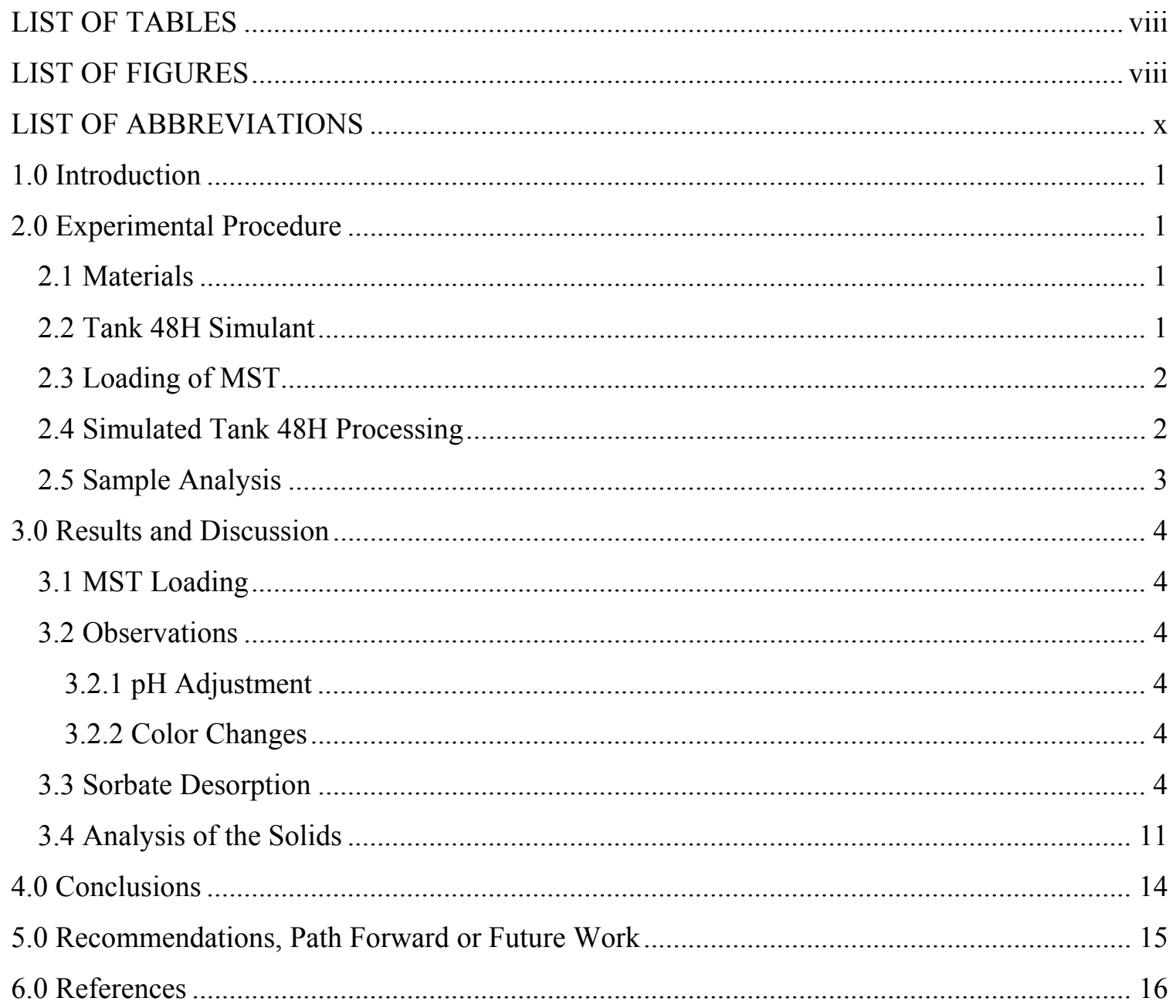




\section{LIST OF TABLES}

Table 2-1. Composition of Tank 48H Simplified Simulant ....................................................... 2

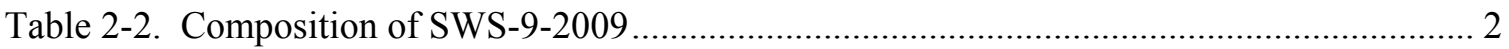

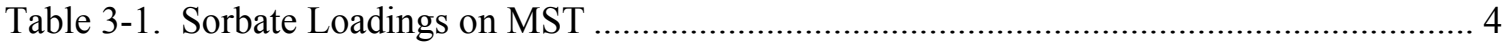

Table 3-2. Measured sorbate concentrations after dissolution of solids in sulfuric acid............. 14

Table A-1. Average Moles of Peroxide versus Ti and Sorbates............................................ A-2

\section{LIST OF FIGURES}

Figure $3-1 .{ }^{85} \mathrm{Sr}$ activity in solution during simulated Tank $48 \mathrm{H}$ processing. .............................. 5

Figure 3-2. Pu concentration in solution during simulated Tank $48 \mathrm{H}$ processing. ........................ 6

Figure 3-3. Np concentration in solution during simulated Tank $48 \mathrm{H}$ processing...................... 6

Figure 3-4. U concentration in solution during simulated Tank $48 \mathrm{H}$ processing.......................... 7

Figure 3-5. Ti concentration in solution during simulated Tank $48 \mathrm{H}$ processing. ........................ 8

Figure 3-6. Percentage of each sorbate leached during Test \#1 (Control). .................................. 9

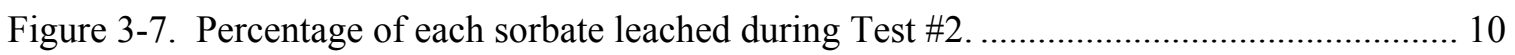

Figure 3-8. Percentage of each sorbate leached during Test \#3 .............................................. 10

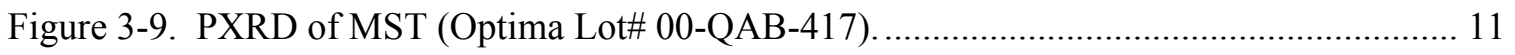

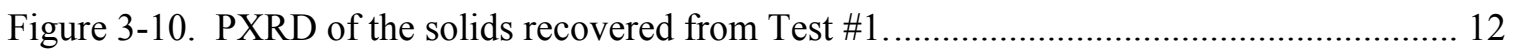

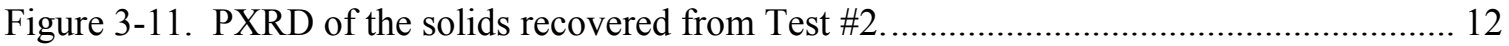

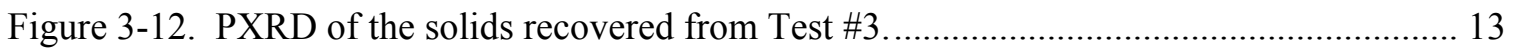

Figure A-1. SEM image of solids isolated from Test \#1 ...................................................... A-2

Figure A-2. EDS results from Raster Scan shown in Figure A-1 .......................................... A-3

Figure A-3. SEM image of solids isolated from Test $\# 1$........................................................ A-3

Figure A-4. EDS analysis of Spot-1 shown in Figure A-3 …............................................... A-4

Figure A-5. EDS analysis of Spot-2 shown in Figure A-3 ….............................................. A-4

Figure A-6. SEM image of solids isolated from Test \#1 ....................................................... A-5

Figure A-7. EDS analysis of Spot-3 shown in Figure A-6 .................................................. A-5 


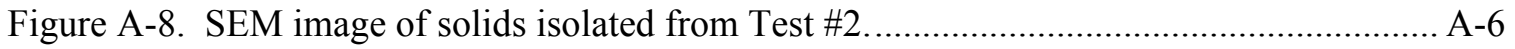

Figure A-9. EDS results from Raster Scan-1 shown in Figure A-8 ....................................... A-6

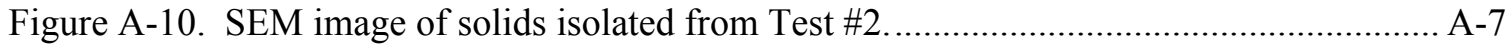

Figure A-11. EDS analysis of Spot-1 shown in Figure A-10 .............................................. A-7

Figure A-12. EDS analysis of Spot-2 shown in Figure A-10 ............................................ A-8

Figure A-13. EDS analysis of Spot-3 shown in Figure A-10 ............................................. A-8

Figure A-14. SEM image of solids isolated from Test \#3 .................................................... A-9

Figure A-15. EDS results from Raster Scan shown in Figure A-14 ........................................ A-9

Figure A-16. SEM image of solids isolated from Test \#3 ..................................................... A-10

Figure A-17. EDS analysis of Spot-4 shown in Figure A-16 ............................................ A-10

Figure A-18. EDS analysis of Spot-5 shown in Figure A-16 ............................................. A-11 
SRNL-STI-2012-00391

Revision 0

\section{LIST OF ABBREVIATIONS}

$\begin{array}{ll}\text { CCPO } & \text { copper catalyzed peroxide oxidation } \\ \text { DWPF } & \text { Defense Waste Processing Facility } \\ \text { FBSR } & \text { Fluidized Bed Steam Reforming } \\ \text { HLW } & \text { High Level Waste } \\ \text { ICP-ES } & \text { inductively coupled plasma - emission spectroscopy } \\ \text { ICP-MS } & \text { inductively coupled plasma - mass spectroscopy } \\ \text { ITP } & \text { In Tank Precipitation } \\ \text { mMST } & \text { modified monosodium titanate } \\ \text { MST } & \text { monosodium titanate } \\ \text { NaTPB } & \text { sodium tetraphenylborate } \\ \text { PUREX } & \text { Plutonium/Uranium Extraction } \\ \text { PuTTA } & \text { plutonium thenoyltrifluoroacetone scintillation } \\ \text { PXRD } & \text { powder X-ray diffraction } \\ \text { SEM-EDS } & \text { scanning electron microscopy - energy dispersive spectroscopy } \\ \text { SRNL } & \text { Savannah River National Laboratory } \\ \text { SRR } & \text { Savannah River Remediation, LLC } \\ \text { SRS } & \text { Savannah River Site } \\ \text { TPB } & \text { tetraphenylborate } \\ \text { TTQAP } & \text { Task Technical and Quality Assurance Plan } \\ \text { TTR } & \text { Technical Task Request }\end{array}$




\subsection{Introduction}

At SRS, Tank 48H currently holds approximately 240,000 gallons of slurry which contains potassium and cesium tetraphenylborate. Original plans called for processing this TPB slurry in the In Tank Precipitation (ITP) Facility, the Late Wash Facility, and the Defense Waste Processing Facility (DWPF) Salt Cell. That process scheme included concentrating the TPB, washing the non-radioactive salts to reduce the nitrite concentration, decomposing the TPB to benzene, and separating the benzene from the aqueous waste. However, these facilities ceased operation due to high benzene generation during startup of the ITP Facility.

In 2001, a team evaluated processing options, which would return Tank $48 \mathrm{H}$ to routine High Level Waste (HLW) service. ${ }^{1}$ The team used the Systems Engineering approach to evaluate the alternatives and make a recommendation to management. The group evaluated 40 options which were subsequently reduced to 15 . A task $\operatorname{plan}^{2}$ detailed the experimental evaluation of these processing options using simple, laboratory scale testing with simulants. Most of the processing focused on three possible decomposition schemes: namely, catalysts, oxidants, and acids.

In June 2009, Fluidized Bed Steam Reforming (FBSR) was designated the technology to remediate Tank $48 \mathrm{H}^{3}{ }^{3}$ Work proceeded until June 2011, when the work was put in suspension until the previous work on decomposition using catalysts, oxidants, and acids could be reevaluated and re-examined for cost effectiveness. ${ }^{4}$

A CCPO process is currently being examined as a method for destroying the TPB present in Tank $48 \mathrm{H}$. In addition to the TPB, Tank $48 \mathrm{H}$ also contains monosodium titanate (MST) that was added during the ITP process to sorb soluble Sr and actinides. Part of the development of the CCPO process includes an examination of the fate of the fissile material during processing. This report details results of experiments designed to examine the fate of the fissile material on the MST currently present in Tank $48 \mathrm{H}$.

This work was performed at the request of Savannah River Remediation, LLC (SRR) ${ }^{5}$ and was controlled by a Task Technical and Quality Assurance Plan (TTQAP). ${ }^{6}$ This report covers only a portion of the work detailed in the referenced Technical Task Request (TTR) and TTQAP. Results from the remaining tasks will be detailed in separate reports.

\subsection{Experimental Procedure}

\subsection{Materials}

The MST used in these studies was prepared using a sol-gel process developed at SRNL and supplied by Optima Chemical Group LLC (Douglas, GA, Lot \#00-QAB-417) as a 15 wt \% suspension in water containing $0.10-0.15 \mathrm{M} \mathrm{NaOH}$ and $100-150 \mathrm{mg} \mathrm{L}^{-1} \mathrm{NaNO}_{2}$.

\subsection{Tank 48H Simulant}

A simplified Tank $48 \mathrm{H}$ simulant solution was prepared following the standard recipe, ${ }^{8}$ omitting the solids and organics. Specifically the following components were omitted: sodium tetraphenylborate (NaTBP), Plutonium/Uranium Extraction (PUREX) sludge simulant, MST, biphenyl, diphenyl mercury, and benzene. The composition is shown in Table 2-1 excluding trace metals present at concentrations less than $0.001 \mathrm{M}$. 
SRNL-STI-2012-00391

Revision 0

Table 2-1. Composition of Tank 48H Simplified Simulant

\begin{tabular}{|c|c|}
\hline Component & Target Concentration (M) \\
\hline $\mathrm{Na}^{+}$ & 3.262 \\
\hline $\mathrm{OH}^{-}$ & 1.633 \\
\hline $\mathrm{NO}_{2}{ }^{-}$ & 0.468 \\
\hline $\mathrm{NO}_{3}{ }^{-}$ & 0.215 \\
\hline $\mathrm{CO}_{3}{ }^{2-}$ & 0.455 \\
\hline $\mathrm{AlO}_{2}{ }^{-}$ & 0.073 \\
\hline $\mathrm{PO}_{4}{ }^{3-}$ & 0.005 \\
\hline $\mathrm{SO}_{4}{ }^{2-}$ & 0.003 \\
\hline $\mathrm{Cl}^{-}$ & 0.003 \\
\hline $\mathrm{F}^{-}$ & 0.001 \\
\hline $\mathrm{K}^{+}$ & 0.064 \\
\hline $\mathrm{Si}$ & 0.003 \\
\hline phenol & 0.010 \\
\hline
\end{tabular}

\subsection{Loading of MST}

Samples of MST were loaded with sorbates ( $\mathrm{Sr}, \mathrm{Pu}, \mathrm{Np}$, and $\mathrm{U}$ ) by contacting with a simulated waste solution for 1 week. The composition of the simulated waste solution (SWS-9-2009) is provided in Table 2-2. The simulant had been prepared previously, and was spiked with ${ }^{85} \mathrm{Sr}$ just prior to use in this testing. Three loadings were performed by adding $2.345 \mathrm{~g}$ of a $14.71 \mathrm{wt} \%$ suspension (0.34 g MST) of MST to three 1-L bottles. $860 \mathrm{~mL}$ of SWS-9-2009 was then added to each bottle, and the bottles were stirred at room temperature for 1 week. The final sorbate loadings on the MST were determined by analyzing aliquots of the supernate from each bottle by gamma spectroscopy, plutonium thenoyltrifluoroacetone scintillation (Pu TTA), and inductively coupled plasma - mass spectroscopy (ICP-MS) at the end of the 1 week loading period.

Table 2-2. Composition of SWS-9-2009

\begin{tabular}{||c|c||}
\hline Component & Measured Concentration \\
\hline Free $\mathrm{NaOH}$ & $1.27 \mathrm{M}$ \\
\hline Total $\mathrm{NaNO}_{3}$ & $2.10 \mathrm{M}$ \\
\hline $\left.\mathrm{NaAl}_{3} \mathrm{OH}\right)_{4}$ & $0.389 \mathrm{M}$ \\
\hline $\mathrm{NaNO}_{2}$ & $0.125 \mathrm{M}$ \\
\hline $\mathrm{Na}_{2} \mathrm{SO}_{4}$ & $0.508 \mathrm{M}$ \\
\hline $\mathrm{Na}_{2} \mathrm{CO}_{3}$ & $0.030 \mathrm{M}$ \\
\hline $\mathrm{Total} \mathrm{Na}^{85} \mathrm{Sr}$ & $5.05 \mathrm{M}$ \\
\hline $\mathrm{Total} \mathrm{Sr}$ & $2.43 \mathrm{E}+04 \mathrm{dpm} / \mathrm{mL}$ \\
\hline${ }^{137} \mathrm{Cs}$ & $0.214 \mathrm{mg} / \mathrm{L}$ \\
\hline Total Cs & $1.14 \mathrm{E}+05 \mathrm{dpm} / \mathrm{mL}$ \\
\hline $\mathrm{Pu}$ & $17.9 \mathrm{mg} / \mathrm{L}$ \\
\hline $\mathrm{Np}$ & $142 \mu \mathrm{g} / \mathrm{L}$ \\
\hline $\mathrm{U}$ & $516 \mu \mathrm{g} / \mathrm{L}$ \\
\hline & $10,900 \mu \mathrm{g} / \mathrm{L}$ \\
\hline
\end{tabular}

\subsection{Simulated Tank 48H Processing}

A total of three tests were performed with the loaded MST. Tests \#2 and 3 (duplicates) were subjected to the following sequential process conditions: acid addition, temperature increase to $50{ }^{\circ} \mathrm{C}$, peroxide addition at $50{ }^{\circ} \mathrm{C}$, and $\mathrm{NaOH}$ addition at room temperature to adjust the solution 
to $1 \mathrm{M}$ free hydroxide. A control test (Test \#1) was subjected to each step except that during the $50{ }^{\circ} \mathrm{C}$ hold no peroxide was added.

Two hundred milliliters of the Tank $48 \mathrm{H}$ simplified simulant were added to each of three $500-\mathrm{mL}$ polyethylene bottles. Each of the MST loading bottles (see Section 2.3) was then filtered through a $0.45-\mu \mathrm{m}$ filter to collect the loaded MST. The solids were washed briefly with a few $\mathrm{mL}$ of Tank $48 \mathrm{H}$ simplified simulant. After washing, the MST was transferred to the test bottle by using aliquots of the solution in the test bottle to slurry and transfer the solids from the filter. The time the solids were added was recorded as the start time. A sample was also removed at this point. The test bottles were then transferred to a $25^{\circ} \mathrm{C}$ shaker oven and were shaken at $175 \mathrm{rpm}$. A sample was not taken after briefly washing the loaded solids, as leaching of any sorbates was expected to be minimal. This was confirmed from analysis of the sample taken after the loaded solids were added to the simplified simulant $(t=0$ sample $)$.

Three $60-\mathrm{mL}$ syringes were then filled with $35 \mathrm{~mL}$ of $50 \mathrm{wt} \% \mathrm{HNO}_{3}$ and were loaded into a syringe pump. Tubing was connected from the syringes to the tops of the test bottles. The $50 \mathrm{wt} \% \mathrm{HNO}_{3}$ was then added to the test bottles at a rate of $1.5 \mathrm{~mL}$ per hour. This rate was selected to require approximately 24 hours for the acid addition to complete; however, this is much slower than the acid addition rate used in the Tank $48 \mathrm{H}$ simulant testing (i.e., $\sim 3.6 \%$ of that rate). ${ }^{9}$ The start time of the acid addition was recorded. After approximately 19 hours of acid addition, the $\mathrm{pH}$ of the test bottles was measured with a portable $\mathrm{pH}$ meter. The $\mathrm{pH}$ was measured to be 11.9. Acid addition was continued, and the $\mathrm{pH}$ was checked hourly, until a $\mathrm{pH}$ below 11 was reached. Once a $\mathrm{pH}$ of below 11 was reached, the acid addition was stopped. Approximately $32 \mathrm{~mL}$ of $50 \mathrm{wt} \% \mathrm{HNO}_{3}$ had been added to reach the end point. The final $\mathrm{pH}$ of each test bottle was recorded, and a sample was removed. After sampling, the test bottles were returned to the shaker oven, and the temperature was increased to $50{ }^{\circ} \mathrm{C}$.

Two 60-mL syringes were then filled with $50 \mathrm{wt} \% \mathrm{H}_{2} \mathrm{O}_{2}$ and were loaded into the syringe pump. Tubing was connected from the syringes to Test bottles \#2 and \#3. Test bottle \#1 is a control and did not receive any $\mathrm{H}_{2} \mathrm{O}_{2}$. The peroxide addition was then started at a rate of $0.32 \mathrm{~mL} / \mathrm{h}$, and was then increased to $0.4 \mathrm{~mL} / \mathrm{h} 50$ minutes later. The rate was selected to add the same scaled volume of $\mathrm{H}_{2} \mathrm{O}_{2}$ added in the 2005 demonstration over a time period of 1 week (i.e., a $\sim 6 \mathrm{X}$ accelerated rate). ${ }^{10}$ The accelerated peroxide addition rate is non-conservative with respect to increasing the reaction with MST due to the rate of auto-decomposition of hydrogen peroxide in alkaline media, which increases with increasing peroxide concentration. ${ }^{11}$ The peroxide addition continued for 1 week, until a total of $67.2 \mathrm{~mL}$ of $50 \mathrm{wt} \% \mathrm{H}_{2} \mathrm{O}_{2}$ had been added to each bottle. Samples were removed at the following times during the $\mathrm{H}_{2} \mathrm{O}_{2}$ addition: 1 day, 2 days, 3 days, 6 days, and 7 days after peroxide addition began. After the peroxide addition was complete, the test bottles continued to shake at $50{ }^{\circ} \mathrm{C}$ for 1 week, and two additional samples were removed ( 8 days and 14 days after peroxide addition began).

After the one week hold at $50{ }^{\circ} \mathrm{C}$, the oven temperature was reduced to $25{ }^{\circ} \mathrm{C}$. After the test bottles had cooled to room temperature, the final $\mathrm{pH}$ was measured. Aliquots of $50 \mathrm{wt} \% \mathrm{NaOH}$ were then added to bring the free hydroxide concentration to a target concentration of $1 \mathrm{M}$. After adding the $\mathrm{NaOH}$, the test bottles were shaken overnight. The test bottles were then filtered, and samples of the filtrate were removed for analysis. After air drying, samples of the solids were also submitted for analysis.

\subsection{Sample Analysis}

Filtrate samples were removed periodically and analyzed using inductively coupled plasma emission spectroscopy (ICP-ES), ICP-MS, gamma scan analysis, and PuTTA. Prior to 
submission, the samples were filtered through a $0.1-\mu \mathrm{m}$ syringe filter and were acidified with an equal volume of $5 \mathrm{M} \mathrm{HNO}_{3}$.

Samples of the solids collected at the end of the testing were submitted for powder X-ray diffraction (PXRD) and scanning electron microscopy - energy dispersive spectroscopy (SEMEDS) analyses. In addition, samples of the solids were dissolved in concentrated $\mathrm{H}_{2} \mathrm{SO}_{4}$ and were analyzed using ICP-ES, ICP-MS, gamma scan, and PuTTA analyses.

\subsection{Results and Discussion}

\subsection{MST Loading}

Table 3-1 provides the sorbate loading values for the three samples of MST used in the testing.

Table 3-1. Sorbate Loadings on MST

\begin{tabular}{||c|c|c|c|}
\hline & MST Sample \#1 & MST Sample \#2 & MST Sample \#3 \\
\hline${ }^{\mathbf{8 5}} \mathbf{S r}(\mathbf{d p m} / \mathbf{g})$ & $6.05 \mathrm{E}+07$ & $6.05 \mathrm{E}+07$ & $6.07 \mathrm{E}+07$ \\
\hline $\mathbf{P u}(\boldsymbol{\mu g} / \mathbf{g})$ & 321 & 326 & 319 \\
\hline $\mathbf{N p}(\boldsymbol{\mu g} / \mathbf{g})$ & 613 & 678 & 693 \\
\hline $\mathbf{U}(\boldsymbol{\mu g} / \mathbf{g})$ & 7890 & 8740 & 7740 \\
\hline
\end{tabular}

\subsection{Observations}

\subsection{1 pH Adjustment}

The $50 \mathrm{wt} \%$ nitric acid was added at a rate of $1.5 \mathrm{~mL}$ per hour to each of the three tests bottles. After approximately $29 \mathrm{~mL}$ of acid had been added, the $\mathrm{pH}$ of test bottle \#3 was measured to be 11.89. The acid addition continued, and the $\mathrm{pH}$ of one bottle was measured every hour for the next 4 hours. The $\mathrm{pH}$ was found to slowly decrease over the next three hours, and then drop by 1 $\mathrm{pH}$ unit over the final hour. At hour three the $\mathrm{pH}$ measured 11.54, and at hour four the $\mathrm{pH}$ measured 10.54. The acid addition was then stopped, and the $\mathrm{pH}$ of all three bottles was measured. The $\mathrm{pH}$ of Bottle \#1 was 10.35, the $\mathrm{pH}$ of Bottle \#2 was 10.54, and the $\mathrm{pH}$ of Bottle \#3 was 10.46 .

The $\mathrm{pH}$ of each test bottle was also measured near the end of the experiment, just before addition of $\mathrm{NaOH}$. The $\mathrm{pH}$ was found to decrease slightly from what was measured prior to the peroxide addition, with Bottle \#1 (control) showing the greatest change. The measured $\mathrm{pH}$ of Bottle \#1 was 10.04 , Bottle \#2 was 10.40, and Bottle \#3 was 10.30 .

\subsubsection{Color Changes}

During the acid addition the color of the solution changed from yellow to brown. After the peroxide addition began, the 2 test bottles began to turn back to yellow, while the control bottle (not receiving peroxide) remained brown.

The solids isolated from the control bottle at the end of the experiment were beige in color, while the solids isolated from the 2 test bottles were light yellow.

\subsection{Sorbate Desorption}

As shown in Figure 3-1, a small amount $(\leq 4 \%)$ of ${ }^{85} \mathrm{Sr}$ was found to desorb when the pH was adjusted to $\sim 11$. The solution concentration increased slightly upon the addition of peroxide, but the total percent leached was still below 7\%. The small amount of ${ }^{85} \mathrm{Sr}$ that leached during the 
peroxide addition, appeared to quickly resorb or precipitate during the hold time, and virtually of the ${ }^{85} \mathrm{Sr}$ was gone from the solution after the addition of $\mathrm{NaOH}$.

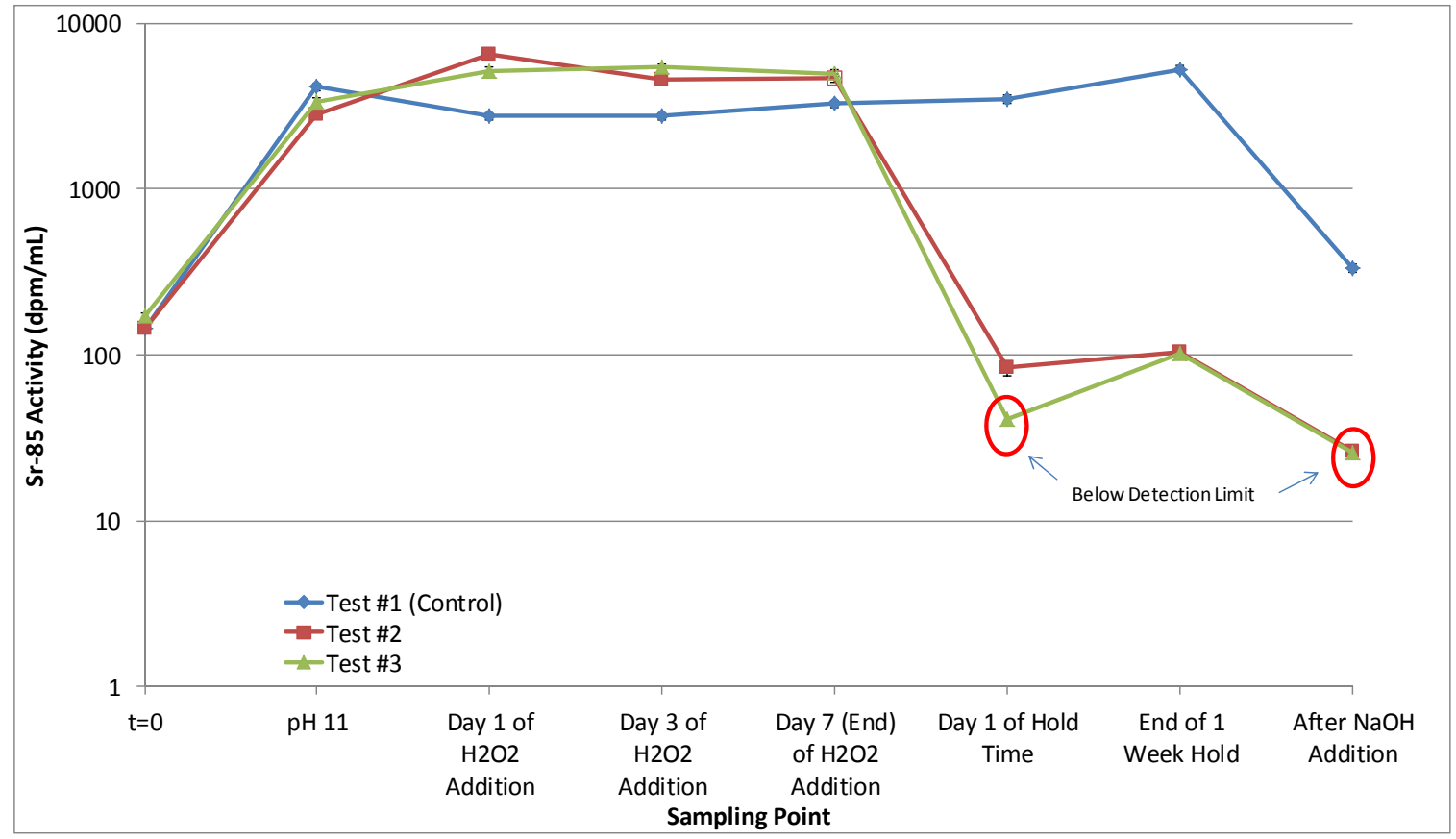

Figure 3-1. ${ }^{85} \mathrm{Sr}$ activity in solution during simulated Tank $48 \mathrm{H}$ processing.

Similarly to ${ }^{85} \mathrm{Sr}$, a small amount ( $\left.\sim 5 \%\right)$ of the Pu was found to desorb after the acid addition (see Figure 3-2). However, after the peroxide addition began, a significant amount of $\mathrm{Pu}$ was found to desorb in the two test bottles, reaching a maximum of $\sim 34 \%$ leached 1 day after the peroxide addition began. In the control bottle, which did not receive any peroxide, the $\mathrm{Pu}$ was found to precipitate or resorb when the temperature was increased to $50{ }^{\circ} \mathrm{C}$. The $\mathrm{Pu}$ in the test bottles remained in solution throughout the peroxide addition, but was gone from solution after 1 day of holding at $50{ }^{\circ} \mathrm{C}$.

As shown in Figure 3-3, a slight increase in the Np solution concentration was also seen after adjusting to a $\mathrm{pH}$ of 11 . For the test bottles, the $\mathrm{Np}$ concentration reached a maximum in solution 1 day after the peroxide addition began. This maximum concentration represents a leaching of $\sim 68-77 \%$ of the $\mathrm{Np}$ from the MST. After reaching this maximum at the beginning of the peroxide addition, the concentration in solution gradually decreased through the remainder of the peroxide addition, the hold time, and the $\mathrm{NaOH}$ addition. The control bottle continued to leach Np into solution during the peroxide addition period, where it was not receiving peroxide, but was at elevated temperature. The control bottle reached a maximum of $\sim 52 \%$ leached at the end of the 1 week hold time. The $\mathrm{Np}$ then precipitated or resorbed upon the addition of $\mathrm{NaOH}$. 
SRNL-STI-2012-00391

Revision 0

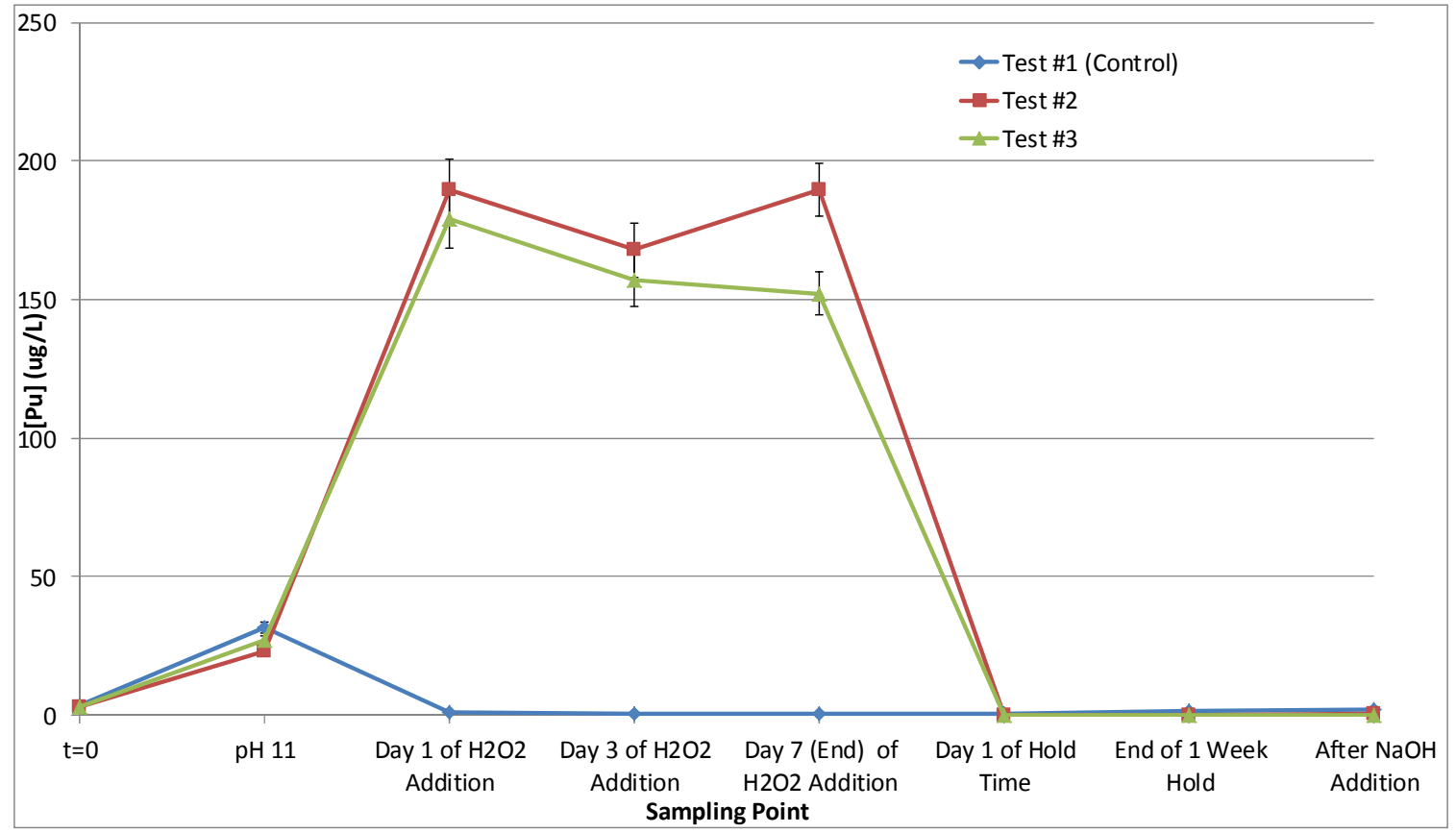

Figure 3-2. Pu concentration in solution during simulated Tank $48 \mathrm{H}$ processing.

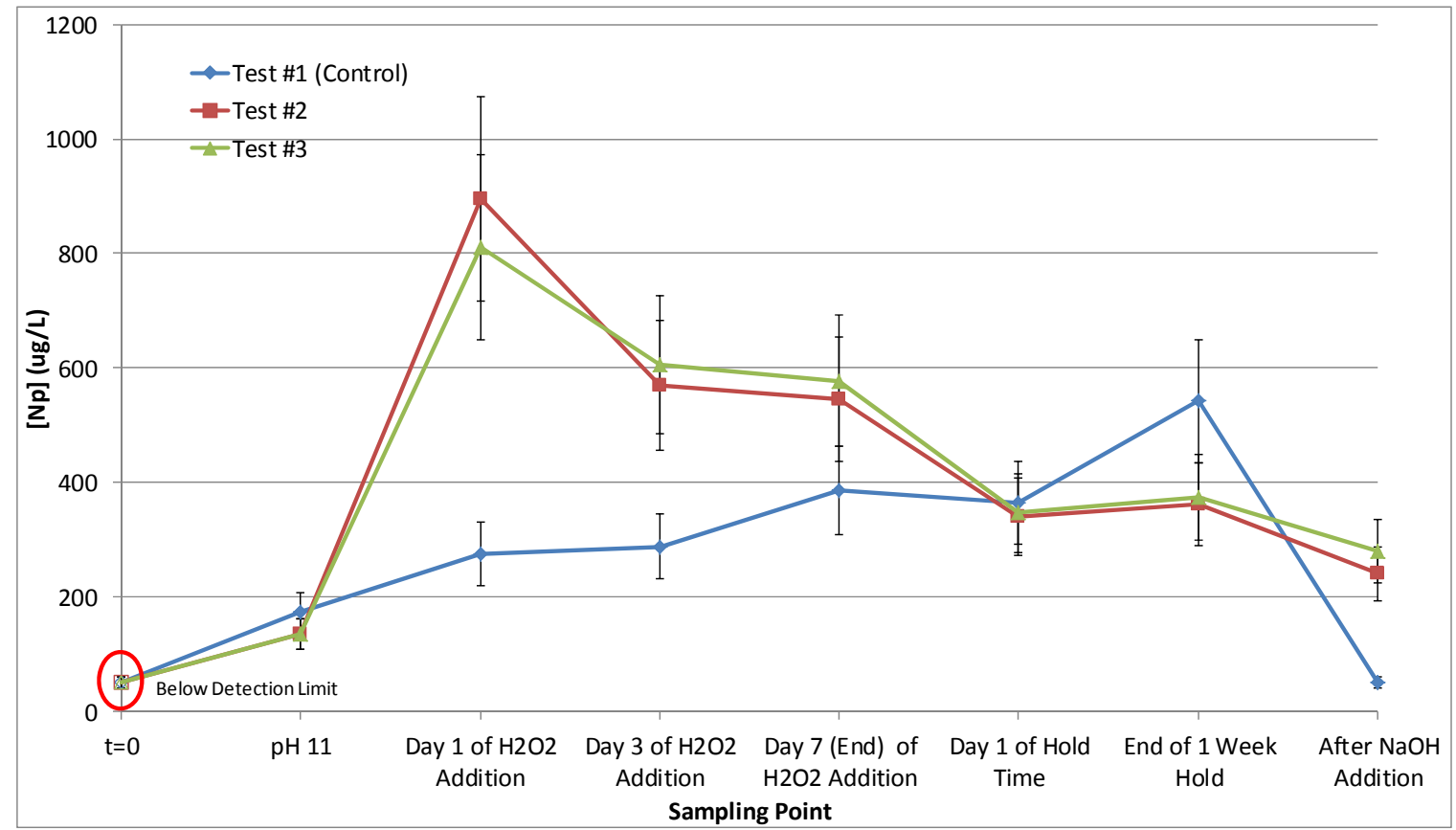

Figure 3-3. Np concentration in solution during simulated Tank $48 \mathrm{H}$ processing.

In the control test, $\mathrm{U}$ began to desorb from the MST after the acid adjustment, and then continued to desorb throughout the remainder of the experiment (see Figure 3-4). The control bottle reached a maximum desorption of $\sim 58 \%$ at the end of the 1 week hold time. A slight decrease in solution concentration was observed after the $\mathrm{NaOH}$ addition; however, the majority of $\mathrm{U}$ 
remained in solution. In the two test bottles, virtually all of the $U$ desorbed at the beginning of the peroxide addition, and remained in solution for the remainder of the experiment, even after $\mathrm{NaOH}$ addition, when the other sorbates were found to precipitate or resorb.

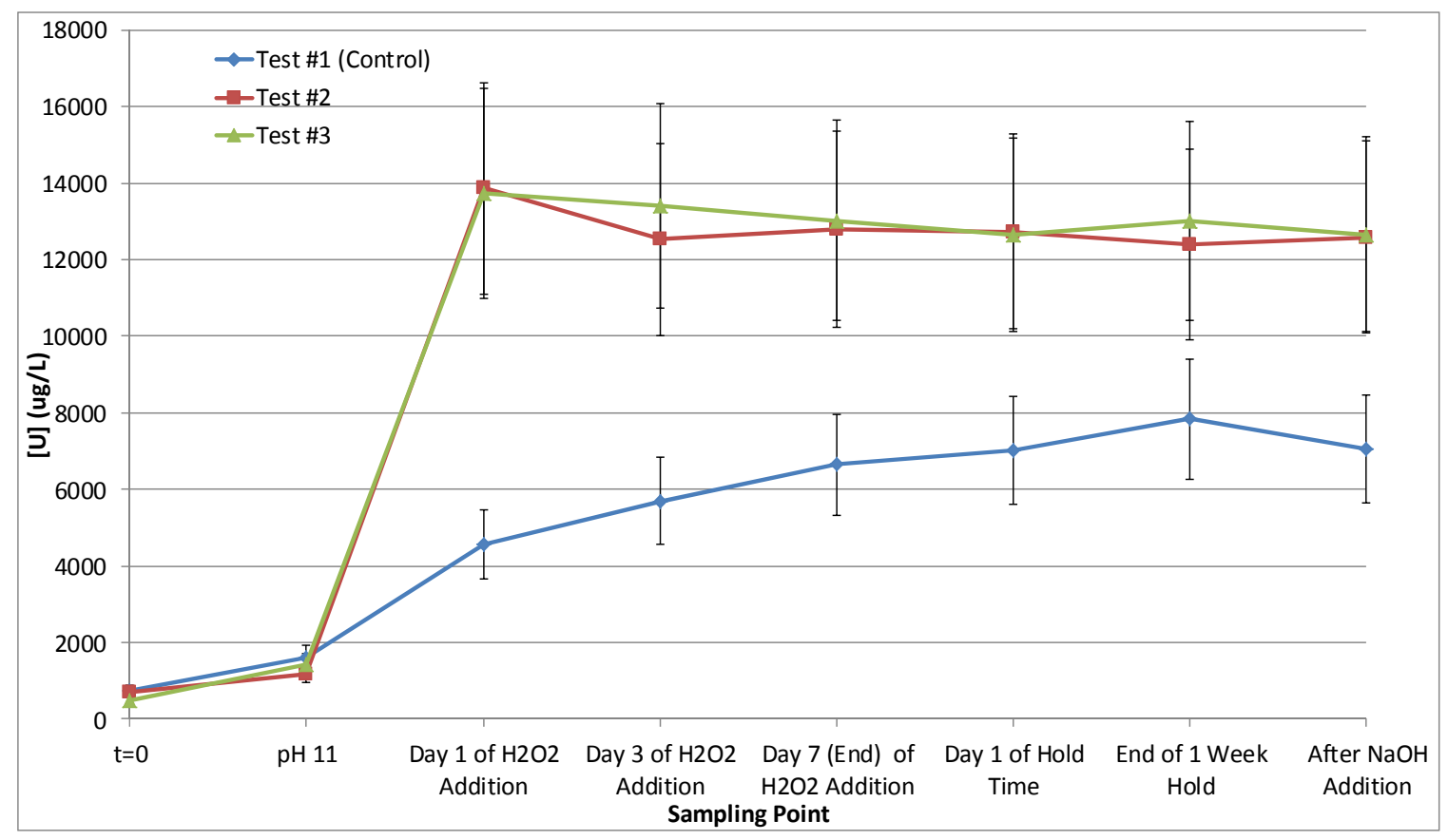

Figure 3-4. $\mathrm{U}$ concentration in solution during simulated Tank $48 \mathrm{H}$ processing.

In addition to monitoring desorption of sorbates throughout the experiment, the concentration of Ti was measured to monitor the dissolution of MST (see Figure 3-5). No MST was observed to dissolve upon $\mathrm{pH}$ adjustment to 11 , or upon a temperature increase to $50{ }^{\circ} \mathrm{C}$ (control sample). However, significant MST dissolution occurred upon the addition of $\mathrm{H}_{2} \mathrm{O}_{2}$. The Ti concentration increased throughout the peroxide addition period, reaching a maximum concentration of $\sim 640$ ppm, which represents dissolution of approximately $78 \%$ of the MST. Assuming the reaction between MST and $\mathrm{H}_{2} \mathrm{O}_{2}$ is first order with respect to MST, the initial rate of the dissolution of MST can be estimated as $2.3 \mathrm{E}-04 \mathrm{~mol} / \mathrm{L} \cdot \mathrm{h}$, with a rate constant of $2.6 \mathrm{E}-02 \mathrm{~h}^{-1}$. The Ti precipitated from solution after the peroxide addition was complete, as the concentration in solution dropped to $\sim 5 \mathrm{ppm}$. Some dissolution of MST in the presence of $\mathrm{H}_{2} \mathrm{O}_{2}$ is expected. During the development of the synthesis for modified MST (mMST), which involves the treatment of MST with $\mathrm{H}_{2} \mathrm{O}_{2}$ to form a peroxo-titanate, some dissolution of the MST was observed, and it was reported that this dissolution was likely due to excess peroxide present in the synthesis. ${ }^{12}$

The soluble Ti concentration in this experiment was much greater than observed in other CCPO experiments performed using the full simulant make-up, including the TPB. In experiments performed with TPB present, the maximum soluble Ti concentration measured was $62 \mathrm{ppm}$, which represents dissolution of $\sim 9.4 \%$ of the MST available. ${ }^{9}$ This test was performed at room temperature with a peroxide addition rate 5 times the nominal rate. These results indicate that the attack of MST by peroxide is significantly suppressed, as expected, by the competing reaction with TPB and other organic components. 


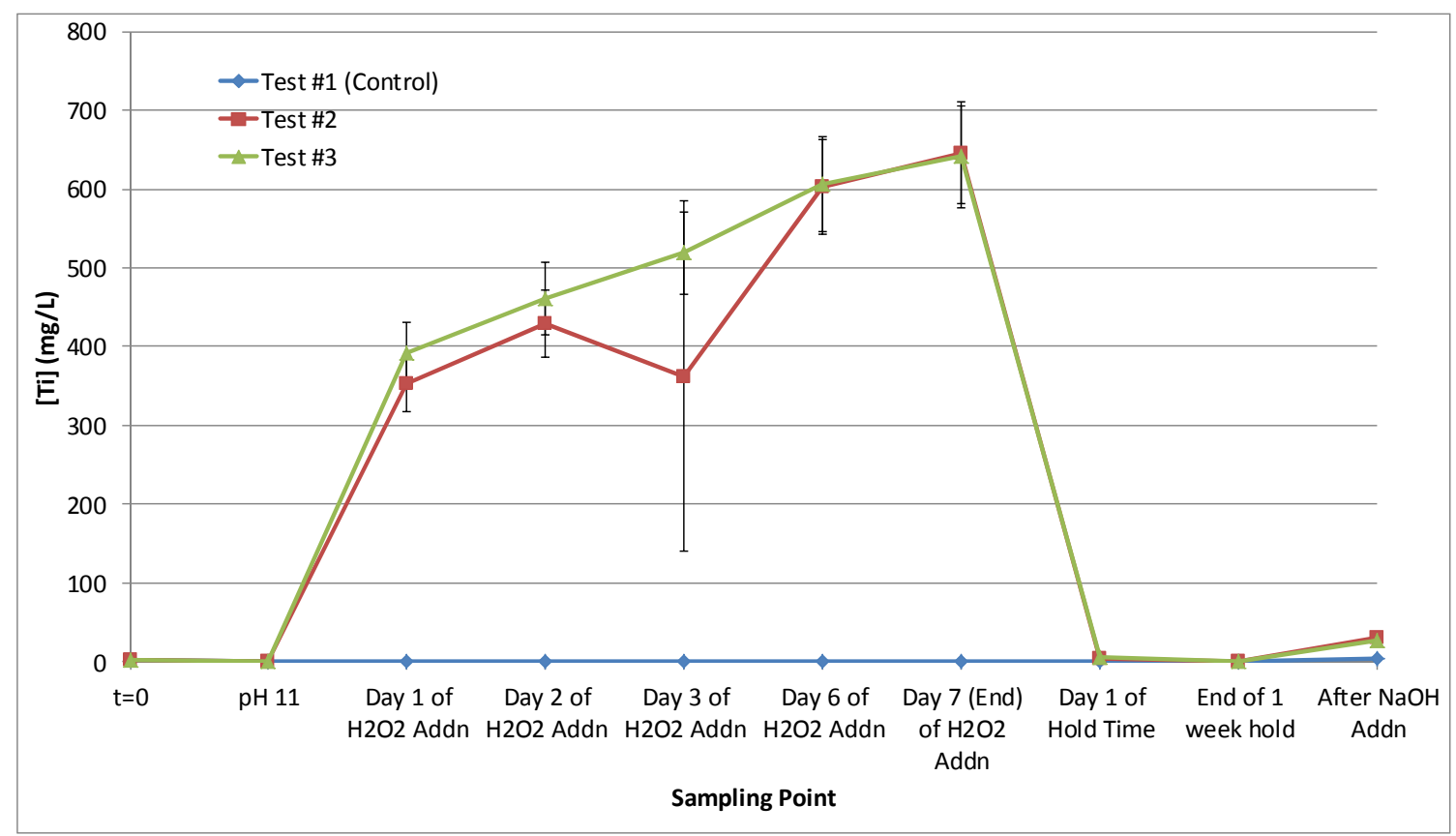

Figure 3-5. Ti concentration in solution during simulated Tank $48 \mathrm{H}$ processing.

The dissolution of MST during the hydrogen peroxide addition is consistent with previous findings investigating the synthesis of mMST. One of the alternate methods tested for synthesizing mMST was dissolution of titanium alkoxide in hot $\left(60{ }^{\circ} \mathrm{C}\right)$, strongly alkaline $\mathrm{H}_{2} \mathrm{O}_{2}$ solution, followed by precipitation of the product. ${ }^{10}$ In this synthesis method titanium isopropoxide was added to a $3 \mathrm{M} \mathrm{NaOH}$ solution at $60{ }^{\circ} \mathrm{C}$, whereupon a white precipitate immediately formed. $\mathrm{H}_{2} \mathrm{O}_{2}$ was then slowly added, dissolving the precipitate to form a clear solution. After the $\mathrm{H}_{2} \mathrm{O}_{2}$ addition was complete, continued stirring of the solution at $60{ }^{\circ} \mathrm{C}$ resulted in precipitation of a yellow solid (peroxotitanate). Formation of the peroxotitanate or mMST would be expected to rapidly resorb the $\mathrm{Pu}$ and $\mathrm{Sr}$ during the 1 week hold time. Since mMST is known to have little affinity for $U$ under these conditions, the observation that $U$ remains in solution is consistent with the formation of mMST upon addition of hydrogen peroxide.

The leaching of $\mathrm{Np}$ and $\mathrm{U}$ in the control sample is likely due to the formation of carbonate complexes. $\mathrm{Np}$ and $\mathrm{U}$ exhibit moderate solubilities in the highly alkaline solution with the formation of anionic hydroxyl species such as $\mathrm{UO}_{2}(\mathrm{OH})_{4}{ }^{2-}$. At lower hydroxide concentrations (i.e., $\mathrm{pH} 8$ to $\mathrm{pH} \sim 11.5$, uranium exhibits higher solubility due the formation of carbonate complexes such as $\mathrm{UO}_{2}\left(\mathrm{CO}_{3}\right)_{3}{ }^{4-13}$. Since the salt solution in contact with the $\mathrm{Sr}$ /actinide-loaded MST solids is very high in carbonate $(0.455 \mathrm{M})$, carbonate is likely serving to strip the $\mathrm{U}$ and $\mathrm{Np}$ from the MST by forming the respective anionic carbonate complexes. Thus, the rate of $U$ and $\mathrm{Np}$ leaching in the control sample can be interpreted as the rate of complexation of $\mathrm{U}$ and $\mathrm{Np}$ by carbonate. After the final $\mathrm{pH}$ adjustment to $1 \mathrm{M}$ free hydroxide, the hydroxide species will again be dominant, allowing for resorption of the U and Np onto the MST. Rapid Np sorption was observed. In contrast, only a slight decrease in the U solution concentration was observed upon holding the mixture for 24 hours after the final $\mathrm{pH}$ adjustment. The sorption of $\mathrm{U}$ onto MST is known to be slow, so a longer hold time would be required to determine if the remaining $\mathrm{U}$ would be sorbed by the MST. Carbonate is also known to complex Pu; however, little Pu leaching was observed in the control sample compared to the leaching of $\mathrm{Np}$ and $\mathrm{U}$. This observation is 
attributed to a stronger interaction between the more highly charged $\mathrm{Pu}^{4+}$ compared to the charge of the monovalent neptunyl, $\mathrm{NpO}_{2}{ }^{+}$, and divalent uranyl cation, $\mathrm{UO}_{2}{ }^{2+}$.

Figures 3-6 through 3-8 show the percentage of each sorbate that desorbed during the experiment, along with the percentage of MST that dissolved (by Ti concentration).

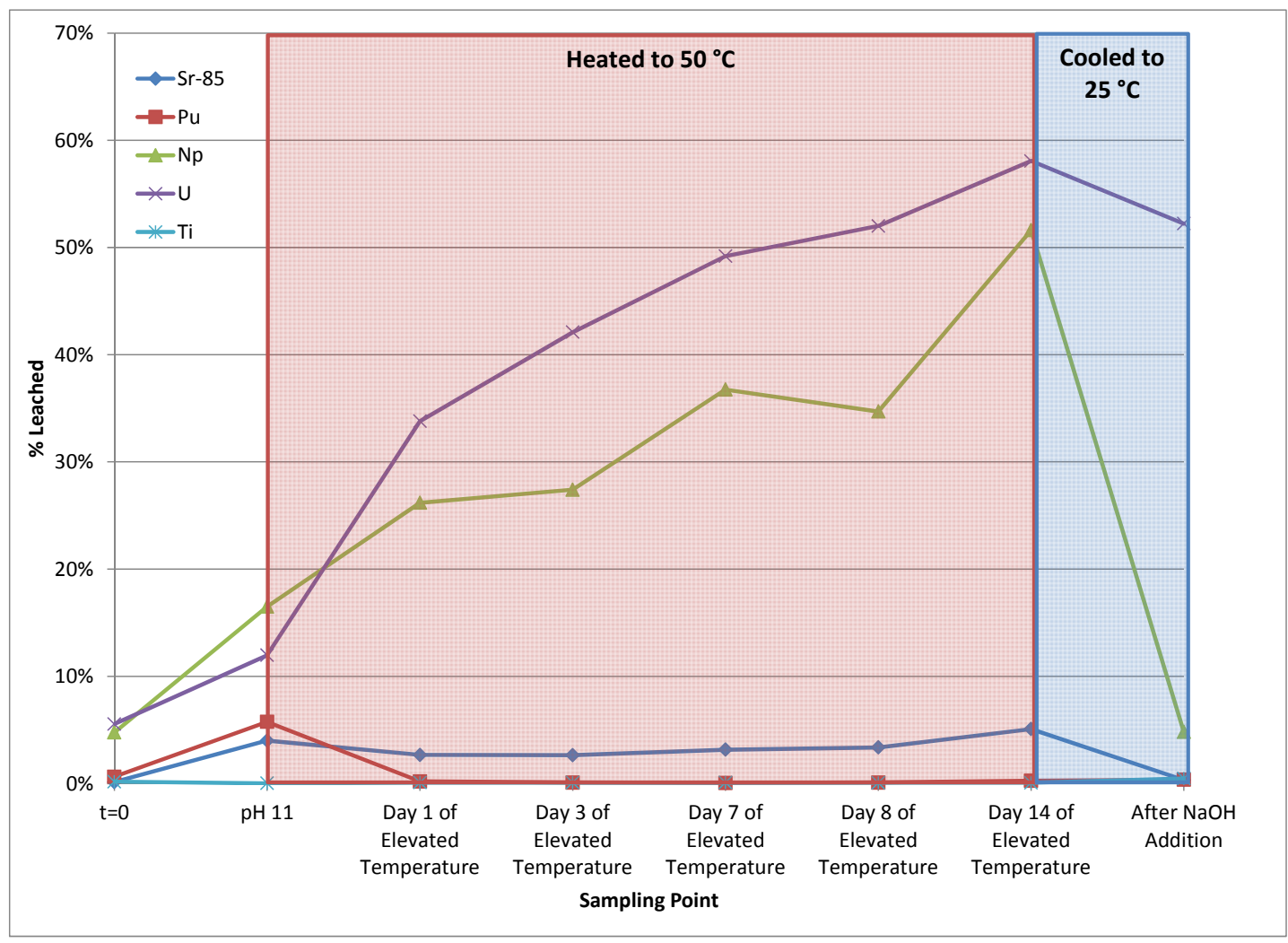

Figure 3-6. Percentage of each sorbate leached during Test \#1 (Control). 


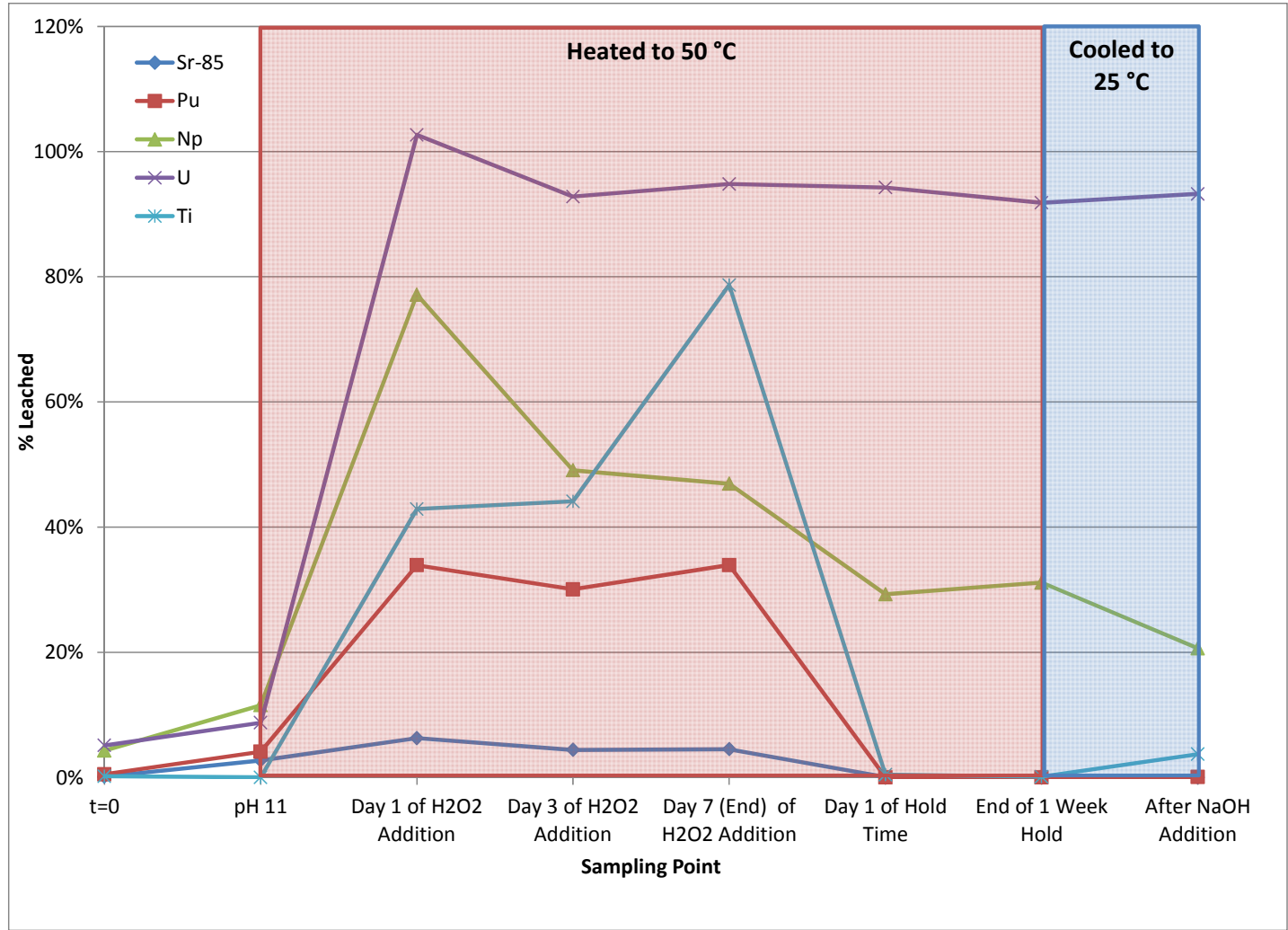

Figure 3-7. Percentage of each sorbate leached during Test \#2.

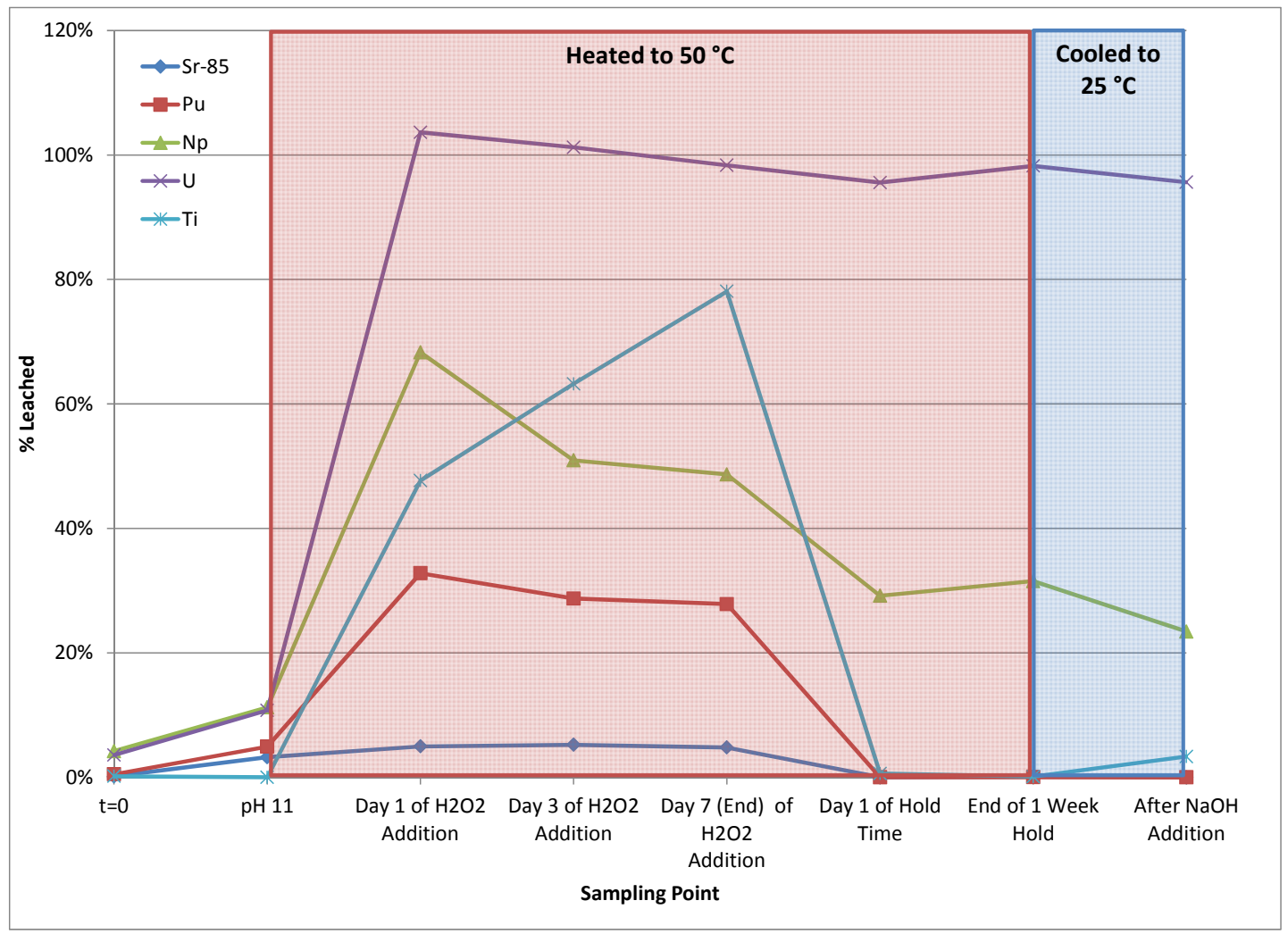

Figure 3-8. Percentage of each sorbate leached during Test \#3. 


\subsection{Analysis of the Solids}

The solids recovered at the end of the experiment, after $\mathrm{NaOH}$ was added to adjust the free hydroxide concentration to $1 \mathrm{M}$, were analyzed by several methods. PXRD analysis was performed to potentially identify the form of the precipitated Ti; however, analysis of the solids showed only the presence of sodium salts $\left(\mathrm{NaNO}_{3}, \mathrm{NaNO}_{2}, \mathrm{Na}_{3} \mathrm{H}\left(\mathrm{CO}_{3}\right)_{2} \cdot 2 \mathrm{H}_{2} \mathrm{O}\right)$ and gibbsite $\left(\mathrm{Al}(\mathrm{OH})_{3}\right)$. Although MST is an amorphous solid, PXRD usually shows evidence of sodium titanium oxide hydroxide $\left(\mathrm{Na}_{2} \mathrm{Ti}_{2} \mathrm{O}_{4}(\mathrm{OH})_{2}\right)$, which was not seen in any of the samples from these experiments. A typical MST PXRD is shown in Figure 3-9, and the PXRD patterns from the solids isolated from Tests \#1-3 are shown in Figures 3-10 through 3-12.

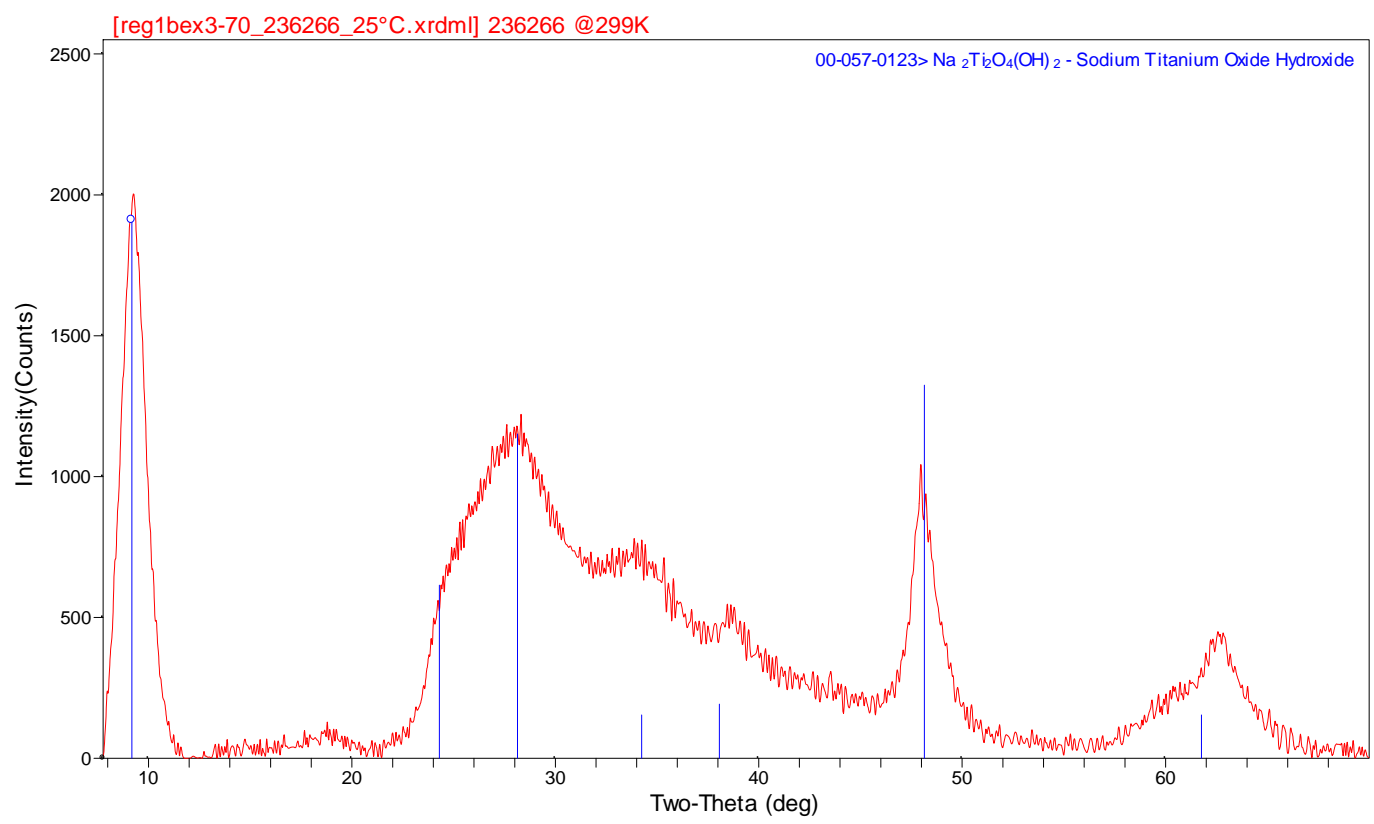

Figure 3-9. PXRD of MST (Optima Lot\# 00-QAB-417). 
SRNL-STI-2012-00391

Revision 0

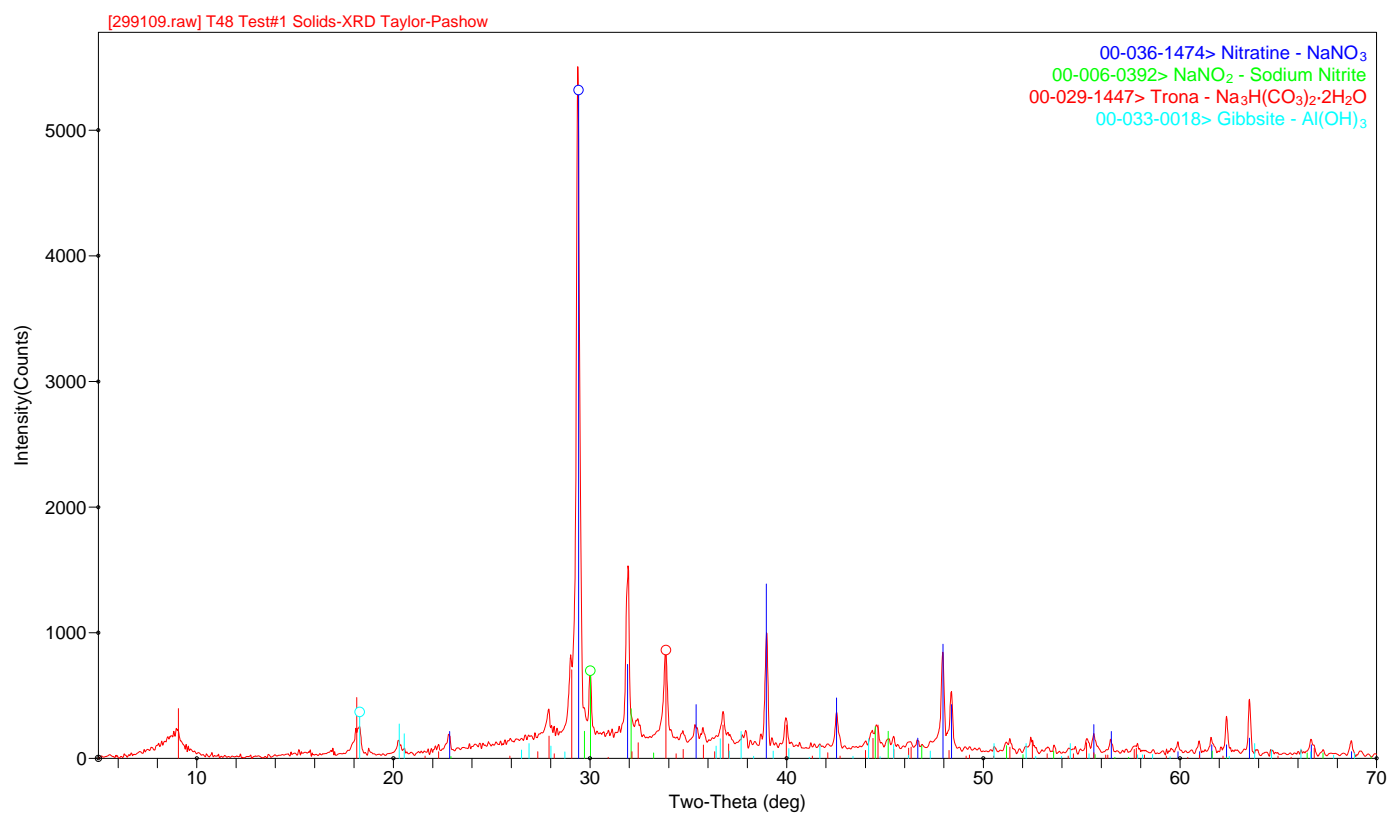

Figure 3-10. PXRD of the solids recovered from Test \#1.

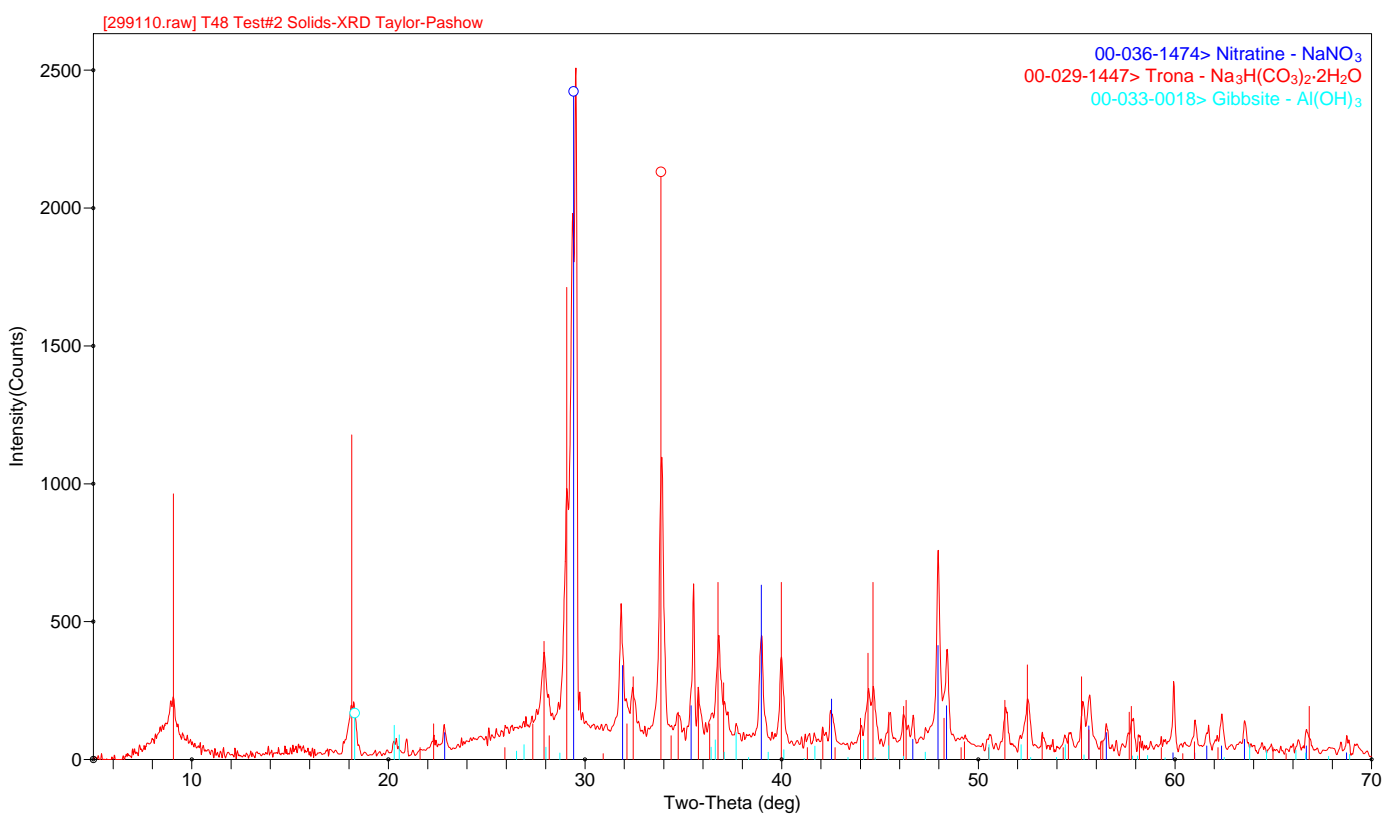

Figure 3-11. PXRD of the solids recovered from Test \#2. 


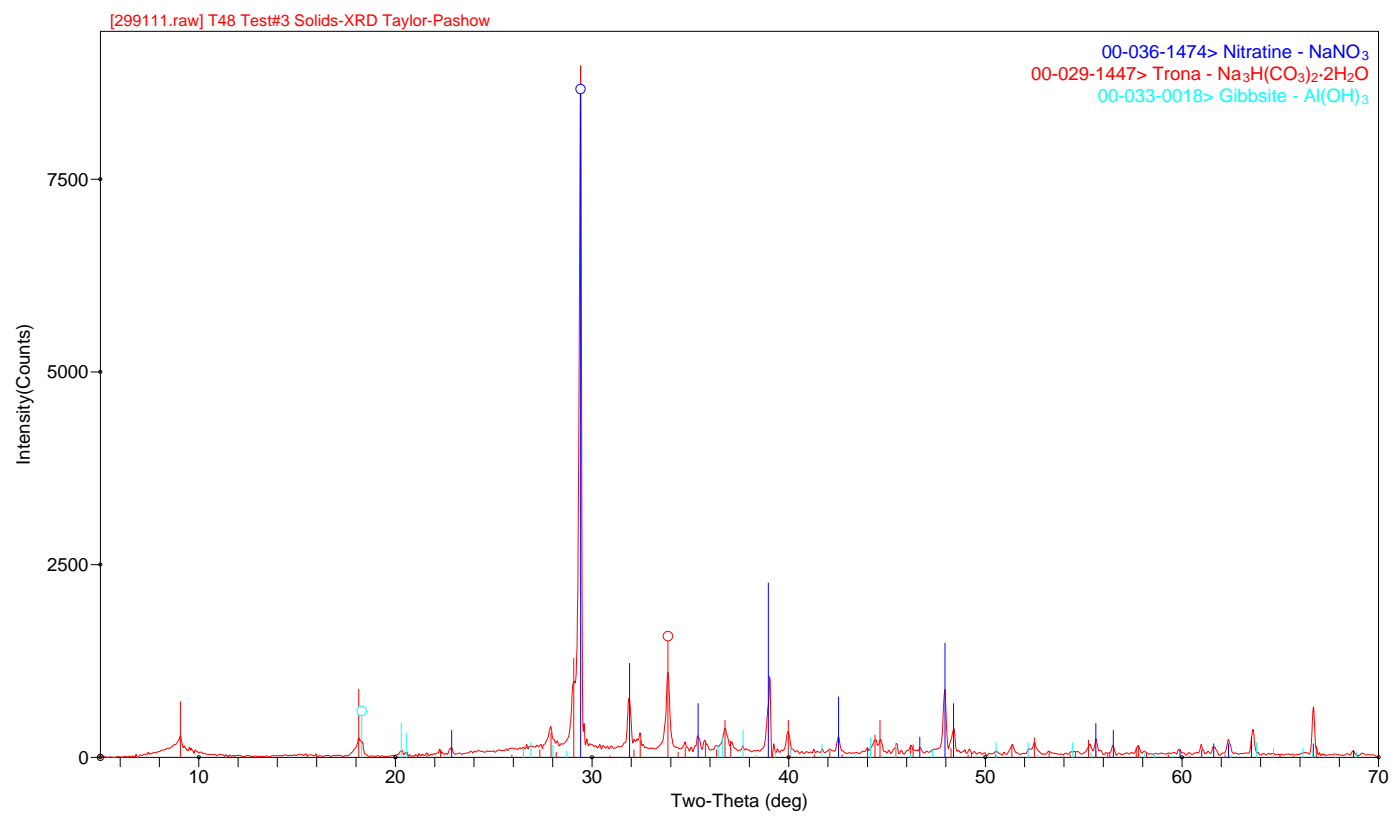

Figure 3-12. PXRD of the solids recovered from Test \#3.

Samples of the solids remaining at the end of the experiments were also analyzed using SEMEDS. EDS analysis did not detect $\mathrm{Pu}$ in any of the samples. The Pu concentration in the samples may be below the detection limit of the method. In the EDS analysis, anything below $1 \mathrm{wt} \%$ is considered trace concentration and may not be detected. If the Pu present was homogeneous throughout the solid, it would be present at $\sim 0.033 \mathrm{wt} \%$. Some U was detected in the solids isolated from Test $\# 1$, but not Tests $\# 2$ and 3. This is consistent with the measured solution concentrations, which indicates virtually all of the U leaches from the MST in Tests \#2 and 3, and remains in solution; whereas about only half of the U leaches from the MST in the control experiment (Test \#1). Representative images and the corresponding EDS spectra are provided in Appendix A. The U concentration in the solids from Test \#1 is estimated to be $\sim 0.14 \mathrm{wt} \%$.

In addition to the above analyses, samples of the solids were also dissolved in concentrated sulfuric acid and analyzed for sorbate concentrations and Ti content. The measured sorbate to Ti ratios are provided in Table 3-2. Using the theoretical amount of Ti in MST, these values were converted to the amount of sorbate per gram of MST, to allow for comparison to the initial loading values reported in Table 3-1. The percentages of the initial loadings are also provided in Table 3-2. These measured values are consistent with the solution concentrations measured after the $\mathrm{NaOH}$ addition. The analyses of the digested solids show that all of the $\mathrm{Sr}$ and $\mathrm{Pu}$ originally loaded on the MST is still present with the solids at the conclusion of the experiment, either resorbed or precipitated. For the control sample, this is also true for $\mathrm{Np}$, while in Tests \#2 and 3, only about $80 \%$ of the Np originally loaded is still present with the solids. This is consistent with the solution analysis, which shows approximately $20 \%$ of the $\mathrm{Np}$ remaining in the solution. For $\mathrm{U}$, the solids from Test \#1 (control) still contain approximately $50 \%$ of the U, while the solids in Tests \#2 and \#3 contain only about 5\%, which again is consistent with the solution analysis. 
Table 3-2. Measured sorbate concentrations after dissolution of solids in sulfuric acid.

\begin{tabular}{|c|c|c|c|}
\hline \multicolumn{4}{|c|}{ Sorbate/Ti Ratios } \\
\hline & Test \#1 & Test \#2 & Test \#3 \\
\hline Sr/Ti (dpm/g) & $1.52 \mathrm{E}+08$ & $1.59 \mathrm{E}+08$ & $1.49 \mathrm{E}+08$ \\
\hline $\mathrm{Pu} / \mathrm{Ti}(\mu \mathrm{g} / \mathrm{g})$ & $7.16 \mathrm{E}+02$ & $9.08 \mathrm{E}+02$ & $8.50 \mathrm{E}+02$ \\
\hline $\mathrm{Np} / \mathrm{Ti}(\mu \mathrm{g} / \mathrm{g})$ & $1.31 \mathrm{E}+03$ & $1.18 \mathrm{E}+03$ & $1.09 \mathrm{E}+03$ \\
\hline $\mathrm{U} / \mathrm{Ti}(\mu \mathrm{g} / \mathrm{g})$ & $7.77 \mathrm{E}+03$ & $7.63 \mathrm{E}+02$ & $8.48 \mathrm{E}+02$ \\
\hline \multicolumn{4}{|c|}{$\begin{array}{l}\text { Sorbate/MST Ratios } \\
\end{array}$} \\
\hline & Test \#1 & Test \#2 & Test \#3 \\
\hline Sr/MST (dpm/g) & $7.30 \mathrm{E}+07$ & $7.61 \mathrm{E}+07$ & $7.16 \mathrm{E}+07$ \\
\hline Pu/MST $(\mu \mathrm{g} / \mathrm{g})$ & $3.43 \mathrm{E}+02$ & $4.35 \mathrm{E}+02$ & $4.08 \mathrm{E}+02$ \\
\hline Np/MST $(\mu \mathrm{g} / \mathrm{g})$ & $6.28 \mathrm{E}+02$ & $5.68 \mathrm{E}+02$ & $5.22 \mathrm{E}+02$ \\
\hline U/MST $(\mu \mathrm{g} / \mathrm{g})$ & $3.72 \mathrm{E}+03$ & $3.66 \mathrm{E}+02$ & $4.06 \mathrm{E}+02$ \\
\hline \multicolumn{4}{|c|}{ Percentage of Initial Loading } \\
\hline & Test \#1 & Test \#2 & Test \#3 \\
\hline $\mathbf{S r}$ & $121 \%$ & $126 \%$ & $118 \%$ \\
\hline $\mathbf{P u}$ & $107 \%$ & $133 \%$ & $128 \%$ \\
\hline $\mathbf{N p}$ & $103 \%$ & $83.7 \%$ & $75.3 \%$ \\
\hline $\mathbf{U}$ & $47.2 \%$ & $4.18 \%$ & $5.25 \%$ \\
\hline
\end{tabular}

\subsection{Conclusions}

The objective of this study was to examine the fate of fissile material in Tank $48 \mathrm{H}$ during the CCPO processing. There are two sources of fissile material - the uranium and plutonium that are sorbed onto the MST and the uranium and plutonium present in the sludge solids. This study only examined the fate of the fissile material on the MST. In addition to the fissile material, the fate of $\mathrm{Sr}$ from the MST was also examined. The study found that leaching begins with the $\mathrm{pH}$ adjustment. Approximately $5 \%$ of the $\mathrm{Pu}$ and $\mathrm{Sr}, 10 \%$ of the $\mathrm{U}$, and $10-15 \%$ of the $\mathrm{Np}$ were found to be in solution after the $\mathrm{pH}$ adjustment. The control test provided information on the leaching behavior of the fissile material at elevated temperature in the absence of peroxide. In this test the small amount of $\mathrm{Pu}$ that desorbed during the $\mathrm{pH}$ adjustment was found to resorb or precipitate upon heating to $50{ }^{\circ} \mathrm{C}$. In contrast, $\mathrm{U}$ and $\mathrm{Np}$ continued to leach throughout the 2 week period at $50{ }^{\circ} \mathrm{C}$. $\mathrm{Np}$ reached a maximum of approximately $52 \%$ leached and $\mathrm{U}$ reached a maximum of approximately $58 \%$ leached. The leached $\mathrm{Np}$ was found to precipitate or resorb after the $\mathrm{NaOH}$ addition, while the leached $\mathrm{U}$ remained in solution. The small amount of $\mathrm{Sr}$ that leached during the $\mathrm{pH}$ adjustment remained in solution, and then precipitated or resorbed after the $\mathrm{NaOH}$ addition. The MST remained intact throughout the experiment for the control sample, indicating that the observed leaching of $\mathrm{U}$ and $\mathrm{Np}$ in this sample is not due to dissolution of the MST. It is likely that after the $\mathrm{pH}$ adjustment to 11 , the formation of carbonate complexes with $\mathrm{Np}$ and $\mathrm{U}$ is resulting in the stripping of these actinides from the MST. The Pu is not stripped due to the stronger interaction of the $\mathrm{Pu}^{4+}$ cation compared to the mono and divalent $\mathrm{NpO}_{2}{ }^{+}$and $\mathrm{UO}_{2}{ }^{2+}$ cations.

In the test bottles both $\mathrm{U}$ and $\mathrm{Pu}$ desorb from the MST when the peroxide addition begins, although to different extents. Virtually all of the $U$ goes into solution at the beginning of the peroxide addition, whereas $\mathrm{Pu}$ reaches a maximum of $\sim 34 \%$ leached during the peroxide addition. Ti from the MST was also found to come into solution during the peroxide addition. Therefore, $\mathrm{Ti}$ is present with the fissile in solution. After the peroxide addition is complete, the $\mathrm{Pu}$ and $\mathrm{Ti}$ are found to precipitate from solution, while the $U$ remains in solution throughout the remaining 
processes, including $\mathrm{pH}$ adjustment to $1 \mathrm{M}$ free hydroxide. It is likely that the Ti precipitates as a peroxotitanate material, which can then resorb leached $\mathrm{Pu}$, but has a low affinity for $\mathrm{U}$. The small amount of $\mathrm{Sr}$ that leached during the $\mathrm{pH}$ adjustment remained in solution throughout the $\mathrm{H}_{2} \mathrm{O}_{2}$ addition and hold time, but precipitated or resorbed after the $\mathrm{NaOH}$ addition. Since $\mathrm{Pu}$ was not detected in the SEM-EDS studies, it cannot be conclusively determined in what form the $\mathrm{Pu}$ returns to the solids. However, since it is likely a peroxotitante phase is formed under these conditions, the $\mathrm{Pu}$ likely resorbed onto this material.

It should also be noted that since the simplified simulant did not contain TPB, all of the peroxide added is available to attack the MST, representing worse case conditions. However, the experiment may be non-conservative in the fact that the peroxide was added at a faster rate, which leads to a higher rate of auto-decomposition of the peroxide. In addition the absence of the $\mathrm{Cu}$ catalyst may also be non-conservative assuming the $\mathrm{Cu}$-peroxide active intermediate is more reactive than the peroxide radical itself.

\subsection{Recommendations, Path Forward or Future Work}

SRNL recommends the following experiments to further examine the fate of fissile material in CCPO processing of Tank $48 \mathrm{H}$.

- Repeat with full simulant matrix (organic and $\mathrm{Cu}$ catalyst present along with simulated radioactive sludge).

- Repeat of one or more of the above tests after selection of final conditions (i.e., $\mathrm{pH}$, temperature) if they differ from conditions tested. 
SRNL-STI-2012-00391

Revision 0

\subsection{References}

${ }^{1}$ R. A. Adams, D. P. Lambert, R. Fowler, T. B. Peters, G. C. Winship, M. R. Norton, N. P. Malik, and R. J. Bentley, "HLW Tank 48H Disposition Alternatives Identification -- Phase I and II Summary Report”, WSRC-RP-2002-00154, Rev. 1, July 15, 2002.

${ }^{2}$ D. P. Lambert, T. B. Peters, and M. E. Stallings, "Task Technical and Quality Assurance Plan for Tank 48 Decomposition Study”, WSRC-RP-2002-00192, March 19, 2002.

${ }^{3}$ G. C. Winship, "Tank 48 Treatment Process Application of Selection Criteria for Business Decision”, YADS-H-00002, Rev.0, June 1, 2009.

${ }^{4}$ K. B. Burnau, “Tank 48 Treatment Execution Strategy”, WDPD-11-69, June 9, 2011.

${ }^{5}$ S. Simner, "Process Optimization for Cu-Catalyzed Peroxide Oxidation of Tank $48 \mathrm{H}$ Tetraphenylborate", G-TTR-H-00005 Revision 1, February 14, 2012.

${ }^{6}$ T. B. Peters, C. A. Nash, F. F. Fondeur, K. M. L. Taylor-Pashow, T. L. White, D. J. Newell, and S. D. Fink, "Task Technical and Quality Assurance Plan for Process Optimization for CuCatalyzed Peroxide Oxidation of Tank 48H Tetraphenylborate", SRNL-RP-2011-01525, Rev. 1, April 2012.

${ }^{7}$ D. T. Hobbs, M. J. Barnes, R. L. Pulmano, K. M. Marshall, T. B. Edwards, M. G. Bronikowski, and S. D. Fink, (2005) "Strontium and Actinide Separations from High Level Nuclear Waste Solutions Using Monosodium Titanate 1. Simulant Testing." Separation Science and Technology, 40 (15): 3093.

${ }^{8}$ M. R. Williams, "Tank 48 Treatment Project - Preparing/Procuring Tank 48 Simulant”, SRNLPSE-2007-00248, Rev.0, November 14, 2007.

${ }^{9}$ T. B. Peters, J. M. Pareizs, D. J. Newell, F. F. Fondeur, C. A. Nash, and S. D. Fink, "Results of Copper Catalyzed Peroxide Oxidation (CCPO) of Tank 48H Simulants", SRNL-STI-2012-00342, August 2012.

${ }^{10}$ D. P. Lambert, T. B. Peters, and S. D. Fink, "In-Tank Peroxide Oxidation Process for the Decomposition of Tetraphenylborate in Tank 48H", WSRC-TR-2005-00114, Rev. 0, April 2005.

${ }^{11}$ O. Špalek, J. Balej, and I. Paseka, "Kinetics of the Decomposition of Hydrogen Peroxide in Alkaline Solutions", J. Chem. Soc., Faraday Trans. 1, 1982, 78, 2349-2359.

${ }^{12}$ M. Nyman and D. T. Hobbs, "A Family of Peroxo-Titanate Materials Tailored for Optimal Strontium and Actinide Sorption”, Chem. Mater., 2006, 18, 6425 - 6435.

${ }^{13}$ I. Grenthe, H. Wanner, I. Forest, Chemical Thermodynamics of Uranium, North-Holland, Amsterdam, 1992. 
SRNL-STI-2012-00391

Revision 0

Appendix A. Supplemental Data 
Table A-1. Average Moles of Peroxide versus Ti and Sorbates

\begin{tabular}{|c|c|}
\hline Species & Total Moles \\
\hline $\mathrm{H}_{2} \mathrm{O}_{2}$ & 1.182 \\
\hline $\mathrm{Ti}$ & 0.0034 \\
\hline $\mathrm{Sr}$ & $1.51 \mathrm{E}-06$ \\
\hline $\mathrm{U}$ & $1.17 \mathrm{E}-05$ \\
\hline $\mathrm{Np}$ & $9.54 \mathrm{E}-07$ \\
\hline $\mathrm{Pu}$ & $4.60 \mathrm{E}-07$ \\
\hline
\end{tabular}

\section{SEM-EDS Results}

In general it is not possible to tell from the following SEM images if the solids are MST or some other amorphous form of Ti precipitate. The MST particles are on the order of $\sim 1-10$ microns; therefore, the images are of too low magnification to show individual particles.

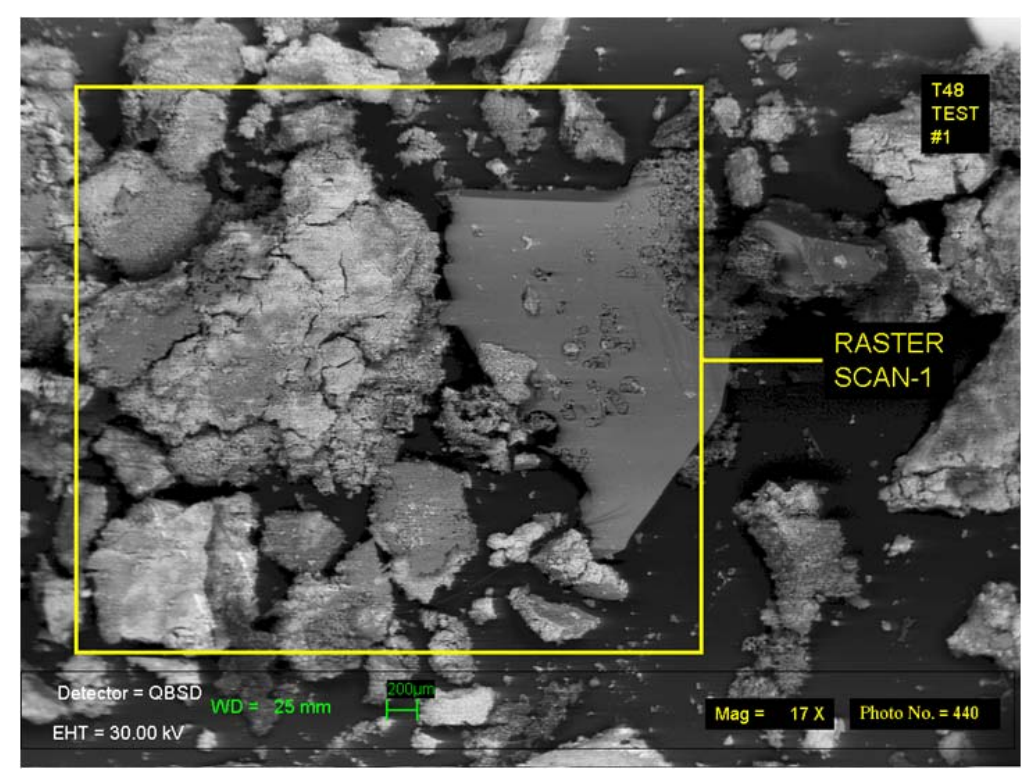

Figure A-1. SEM image of solids isolated from Test \#1. 


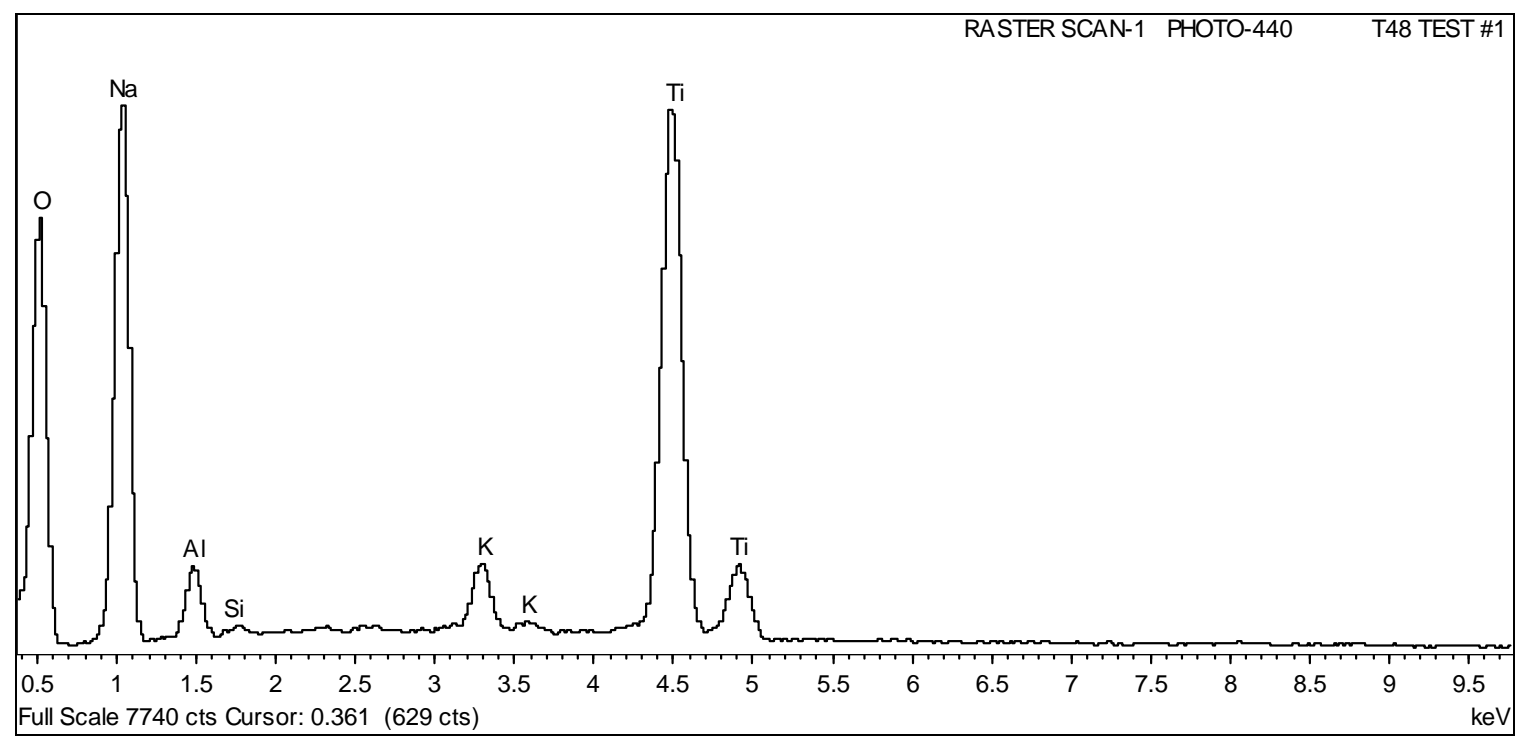

Figure A-2. EDS results from Raster Scan shown in Figure A-1.

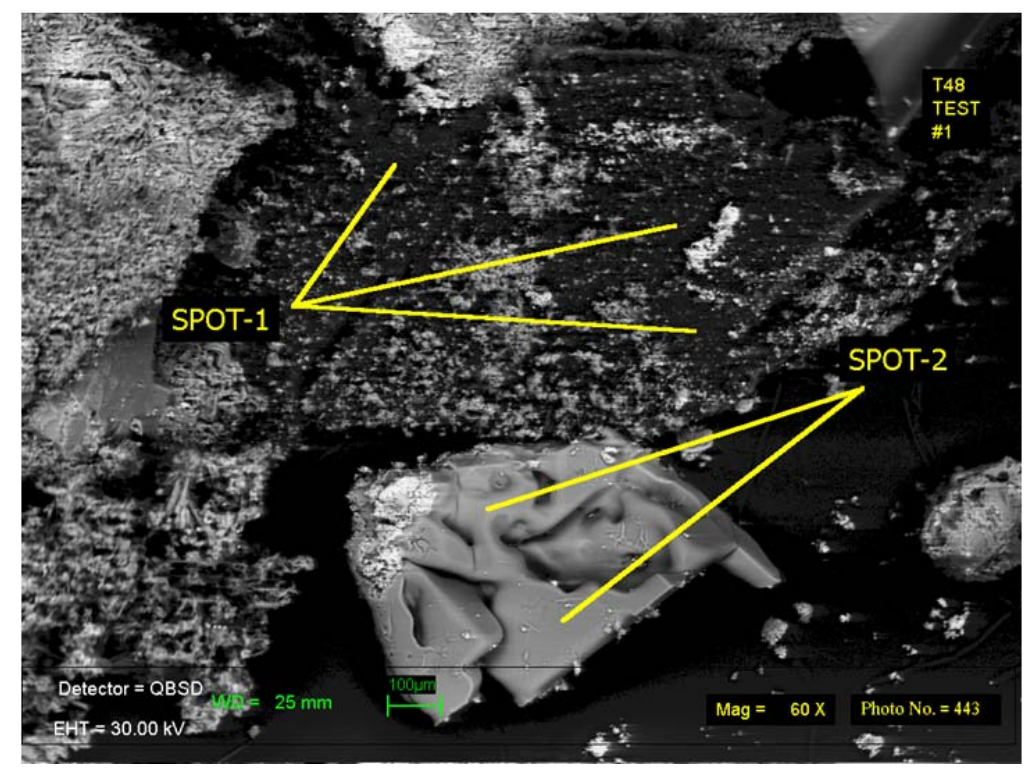

Figure A-3. SEM image of solids isolated from Test \#1. 


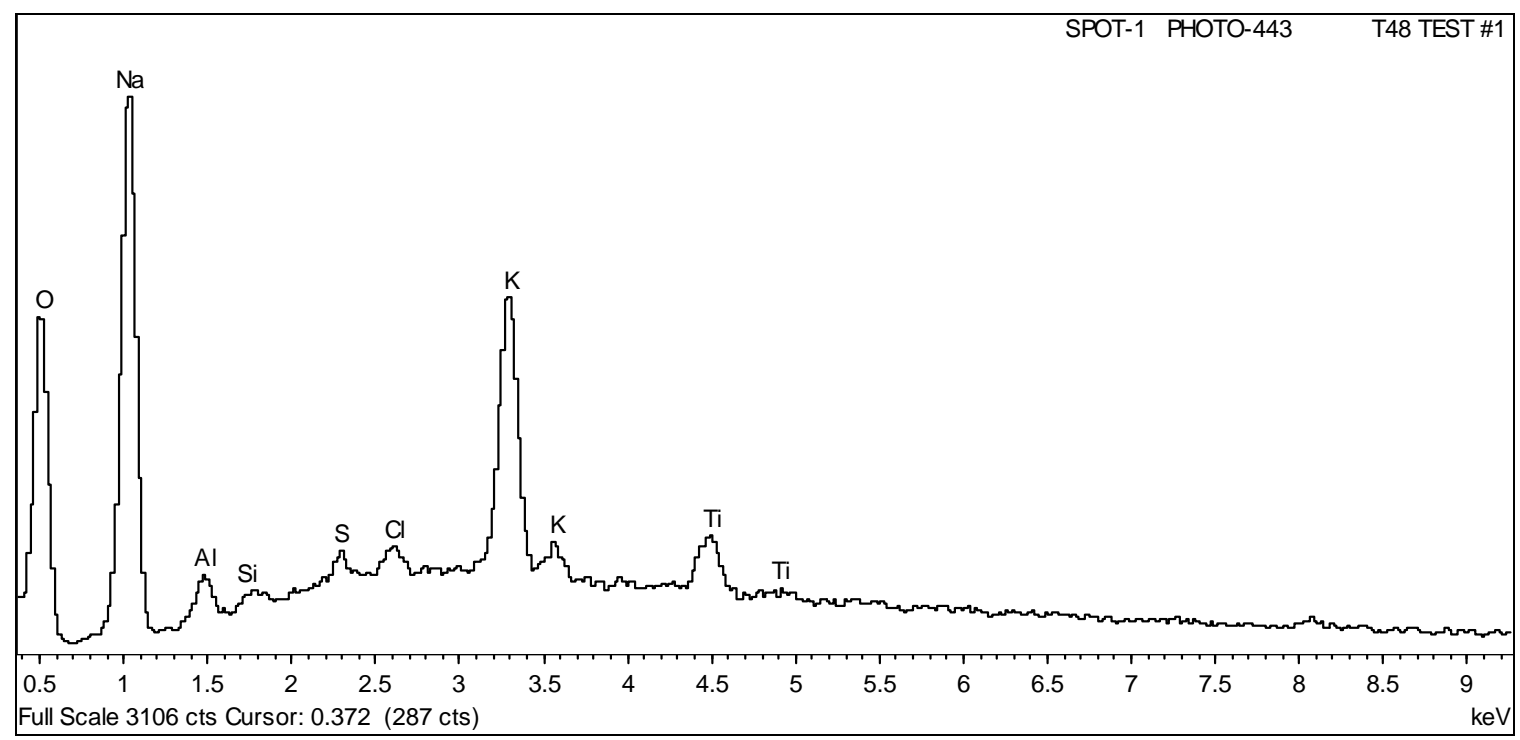

Figure A-4. EDS analysis of Spot-1 shown in Figure A-3.

The EDS spectrum shown in Figure A-5 is indicative of a sodium salt, which could have resulted from residual simulant drying with the solids. This is consistent with the PXRD results which also showed the presence of salts.

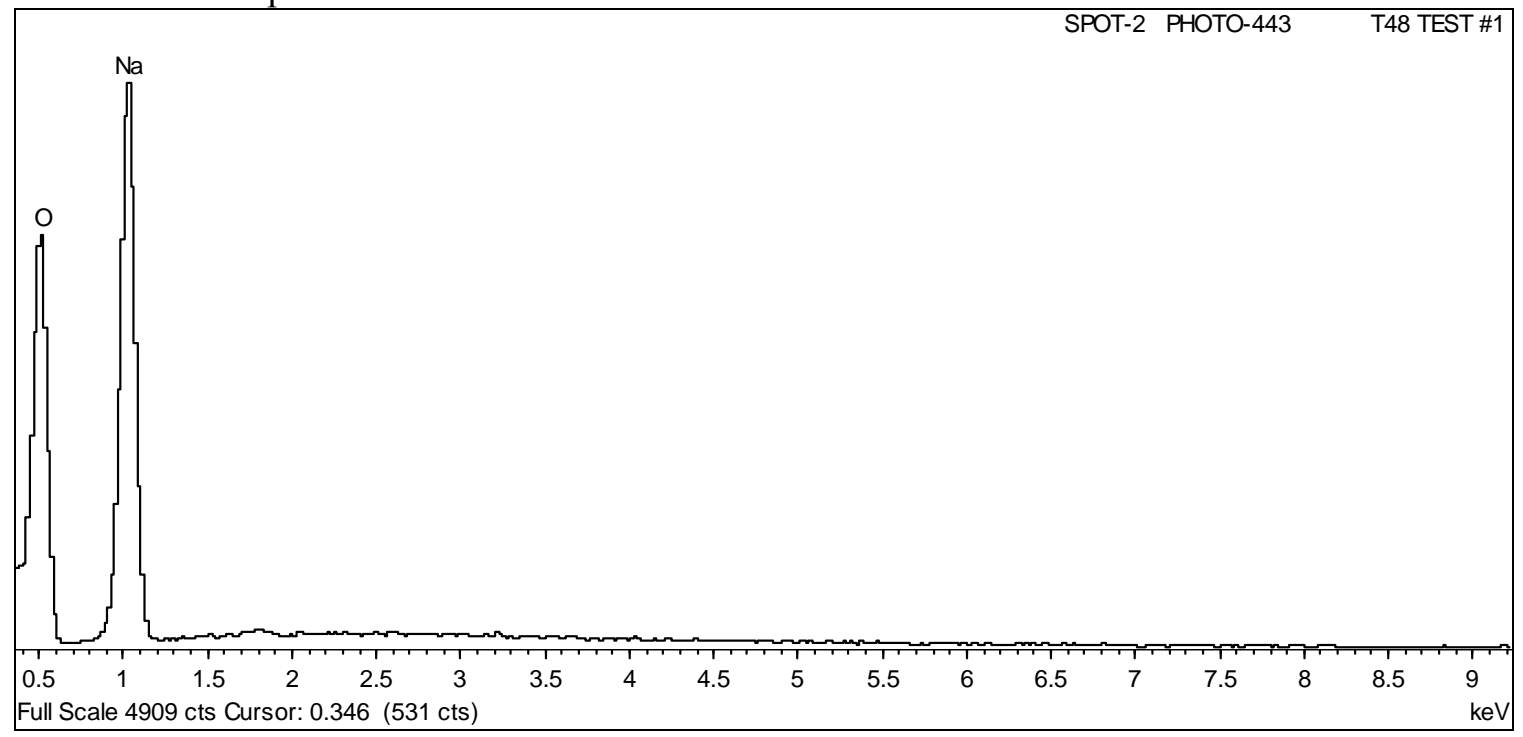

Figure A-5. EDS analysis of Spot-2 shown in Figure A-3.

The bright spots in Figure A-6 suggest $\mathrm{U}$ rich areas, as higher atomic number elements appear as brighter spots in a backscatter SEM image. Solution analysis results for Test \#1 did not indicate desorption followed by precipitation of $U$, which would suggest that the $U$ present in the solids is the $U$ originally loaded on the MST. 


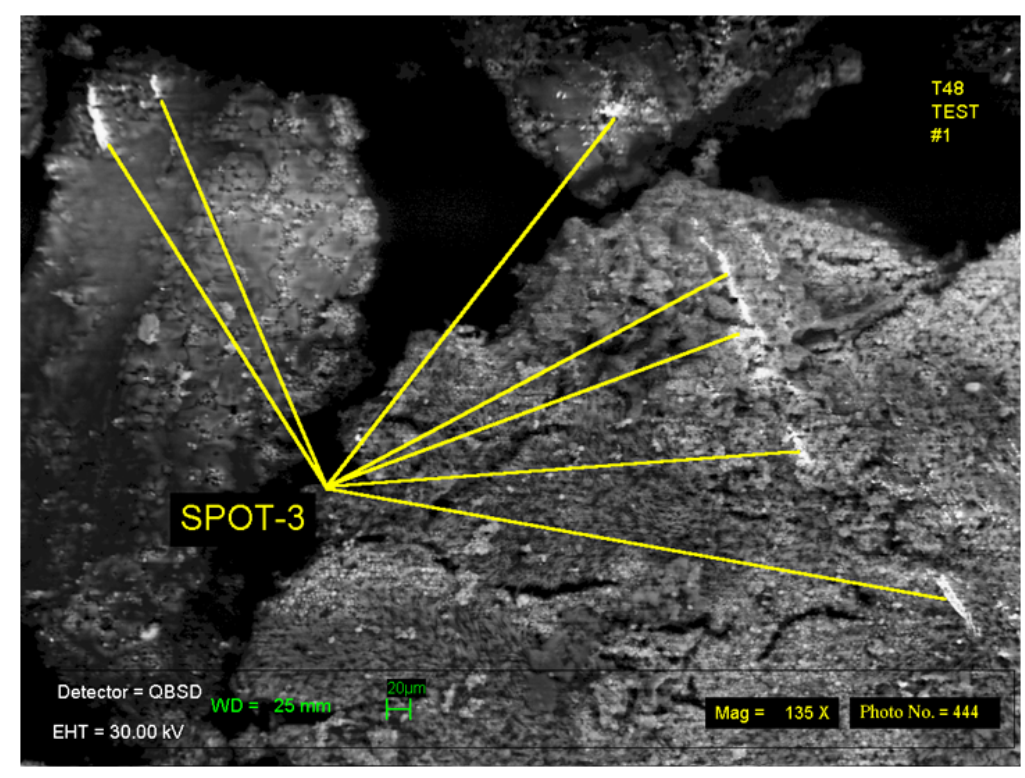

Figure A-6. SEM image of solids isolated from Test \#1.

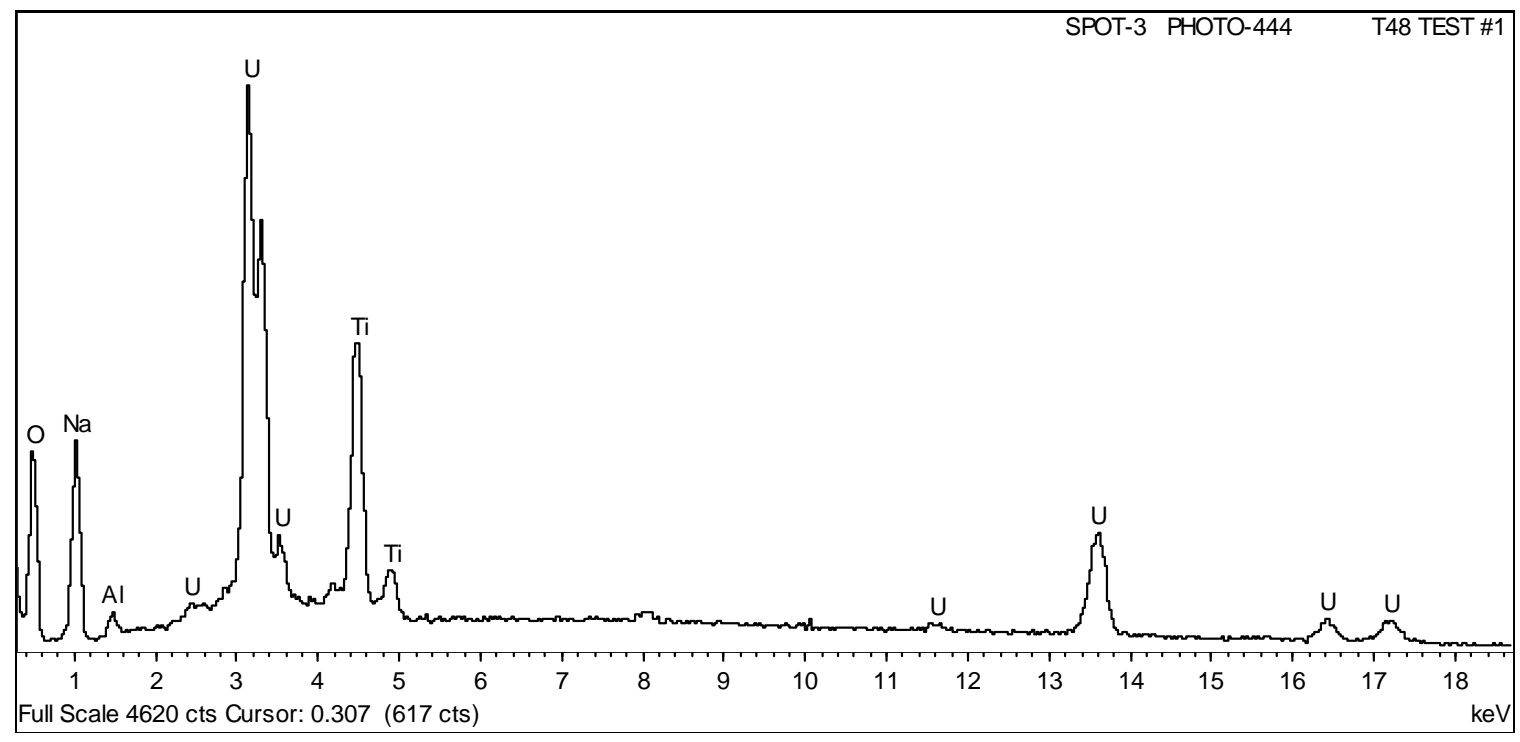

Figure A-7. EDS analysis of Spot-3 shown in Figure A-6. 


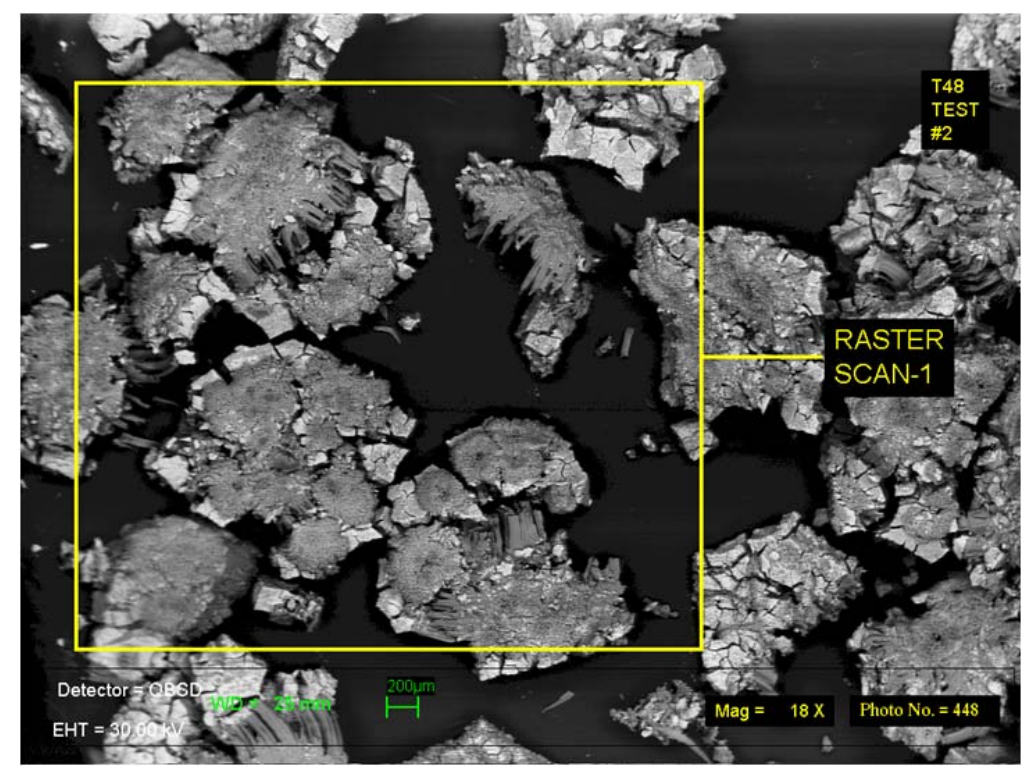

Figure A-8. SEM image of solids isolated from Test $\# 2$.

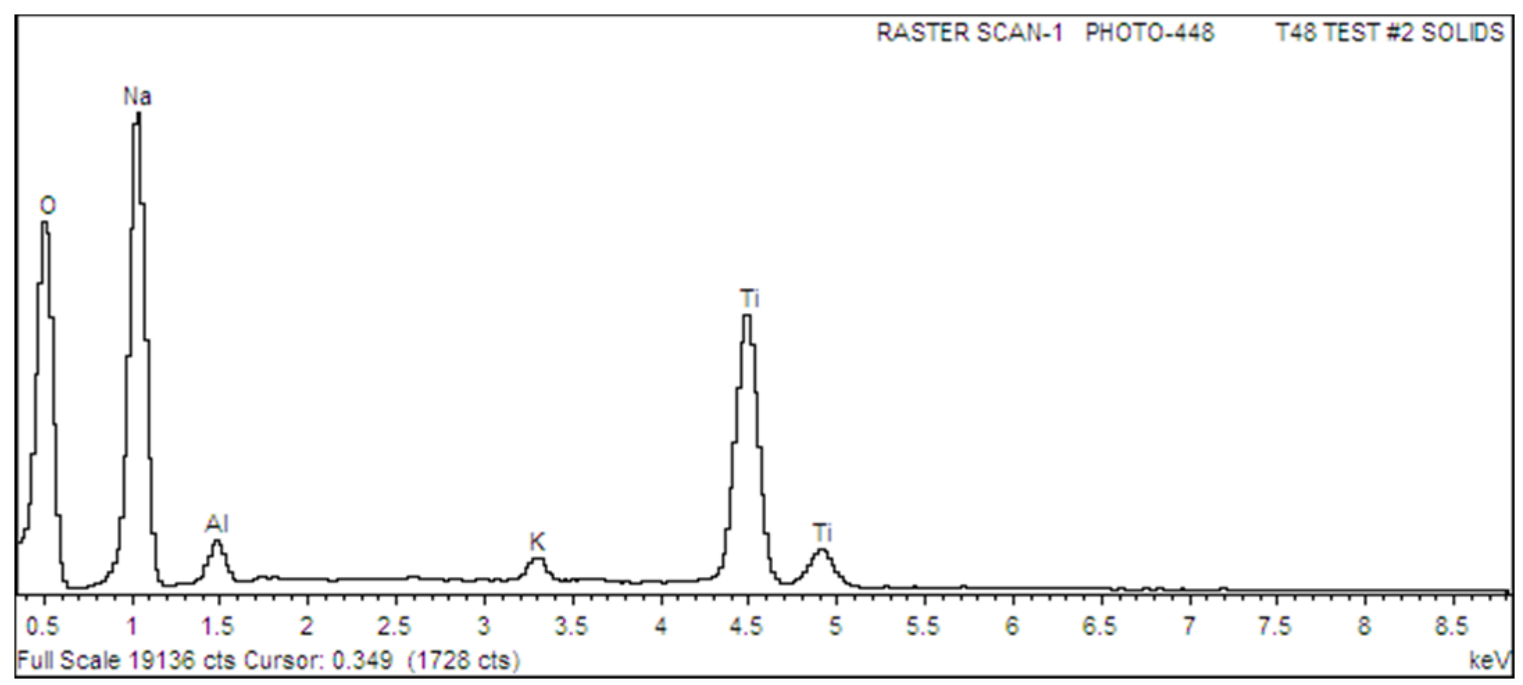

Figure A-9. EDS results from Raster Scan-1 shown in Figure A-8. 


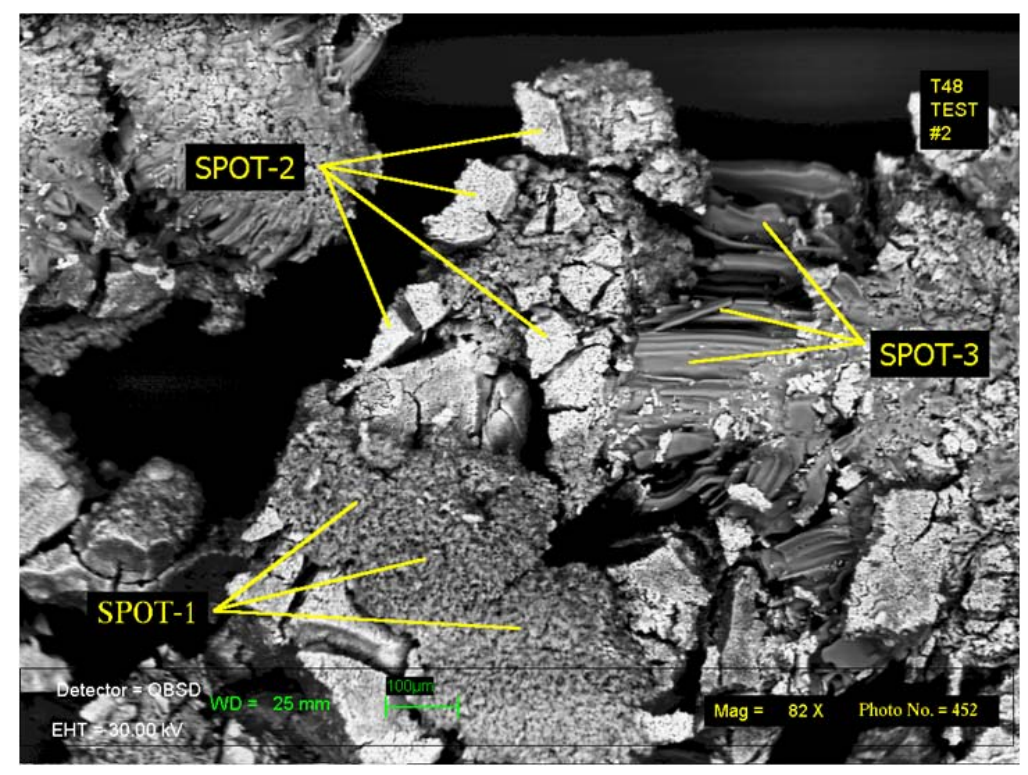

Figure A-10. SEM image of solids isolated from Test \#2.

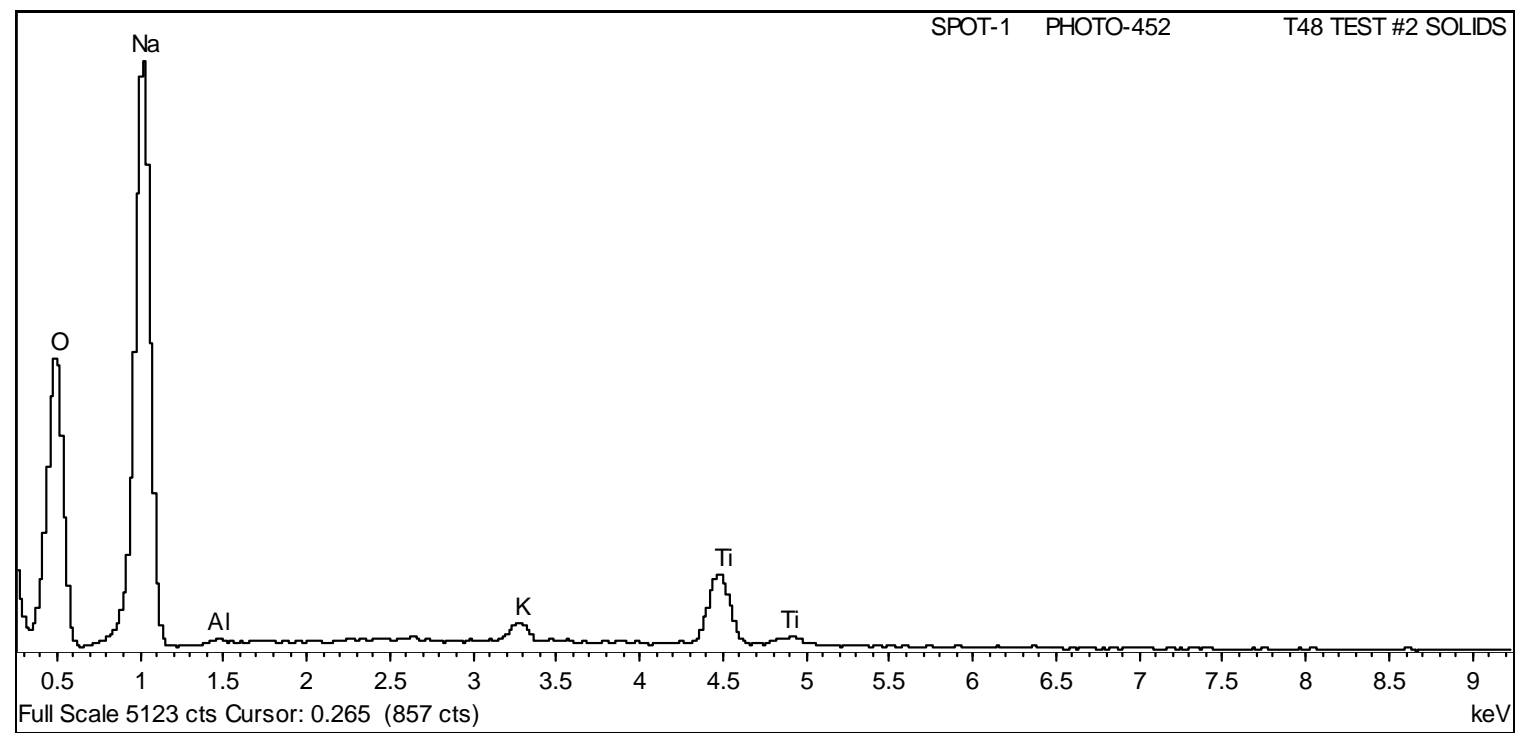

Figure A-11. EDS analysis of Spot-1 shown in Figure A-10. 
SRNL-STI-2012-00391

Revision 0

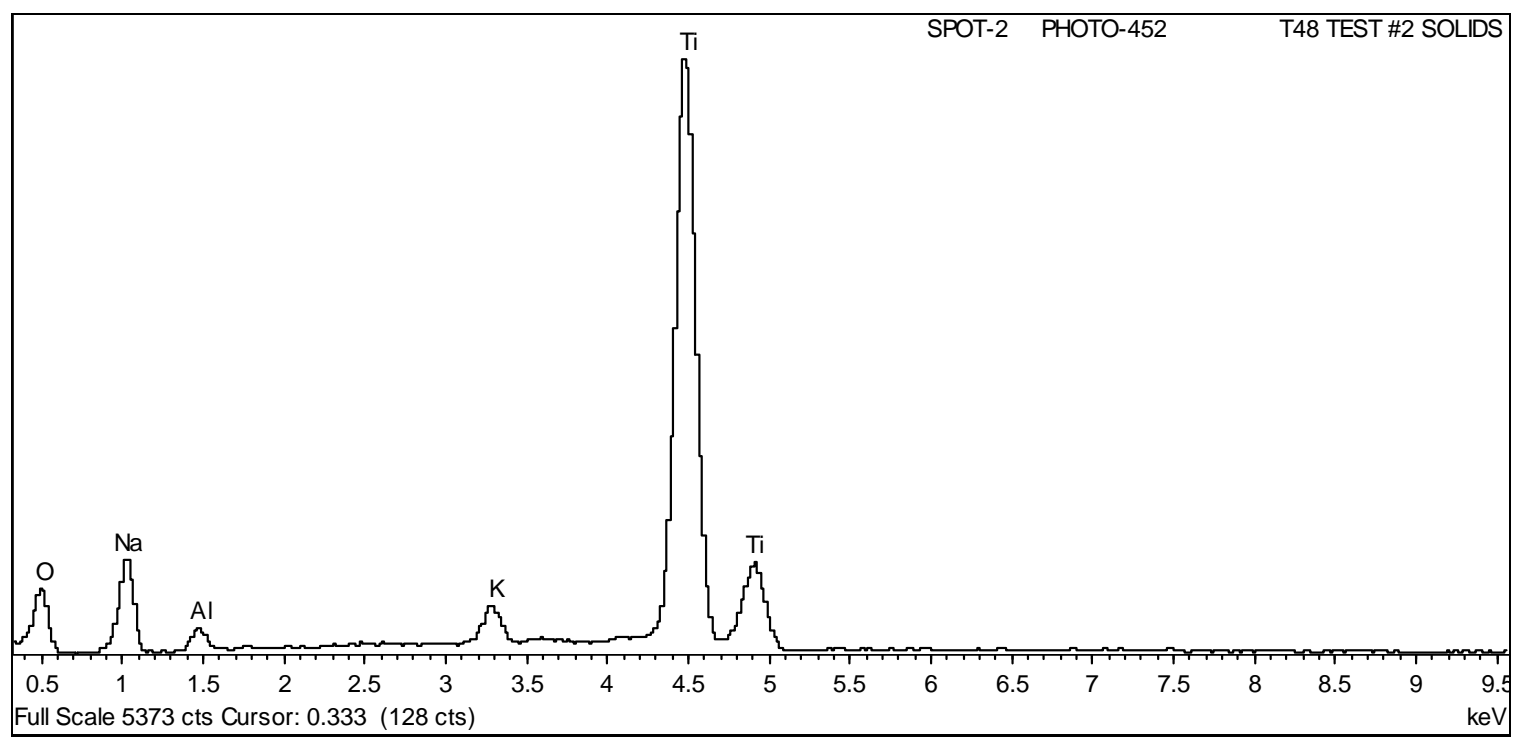

Figure A-12. EDS analysis of Spot-2 shown in Figure A-10.

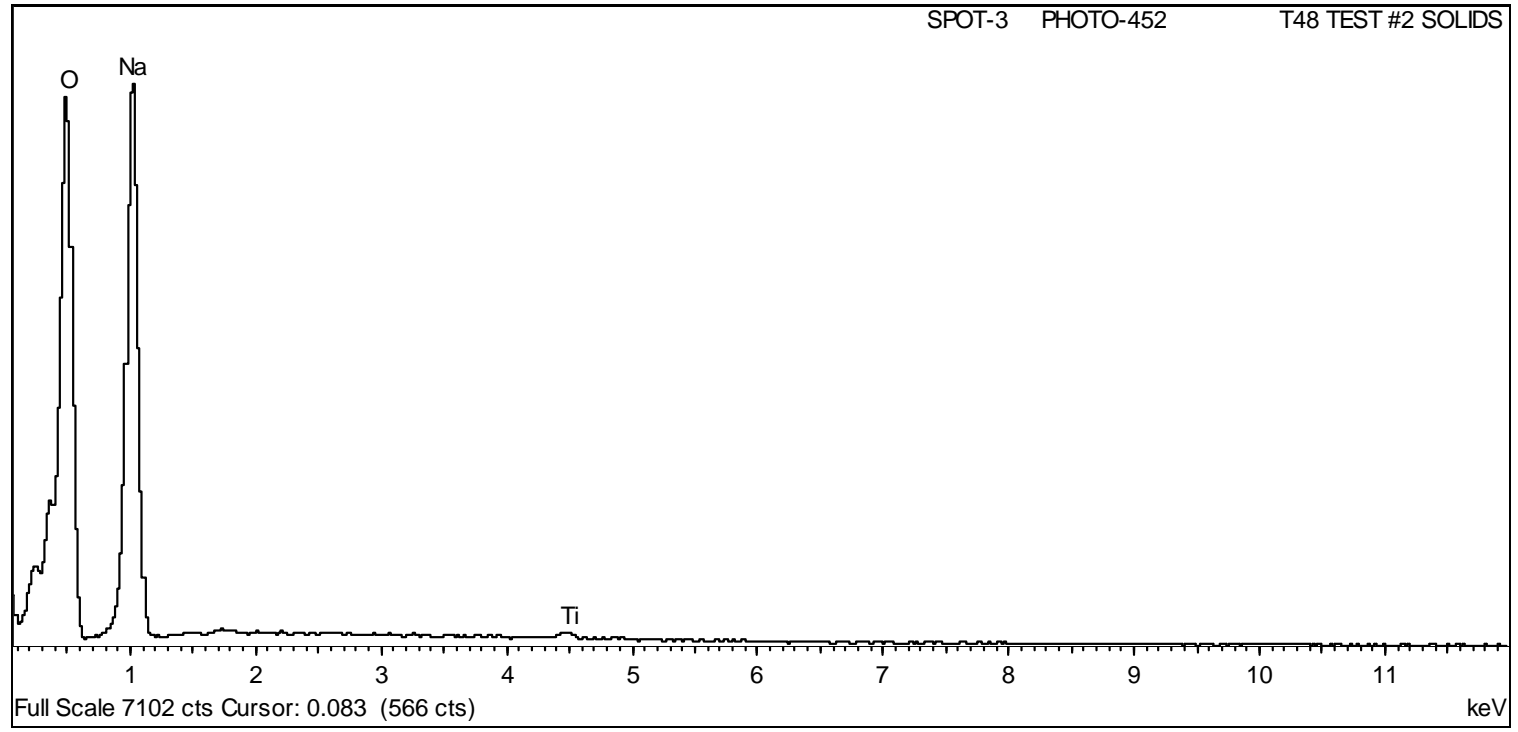

Figure A-13. EDS analysis of Spot-3 shown in Figure A-10. 


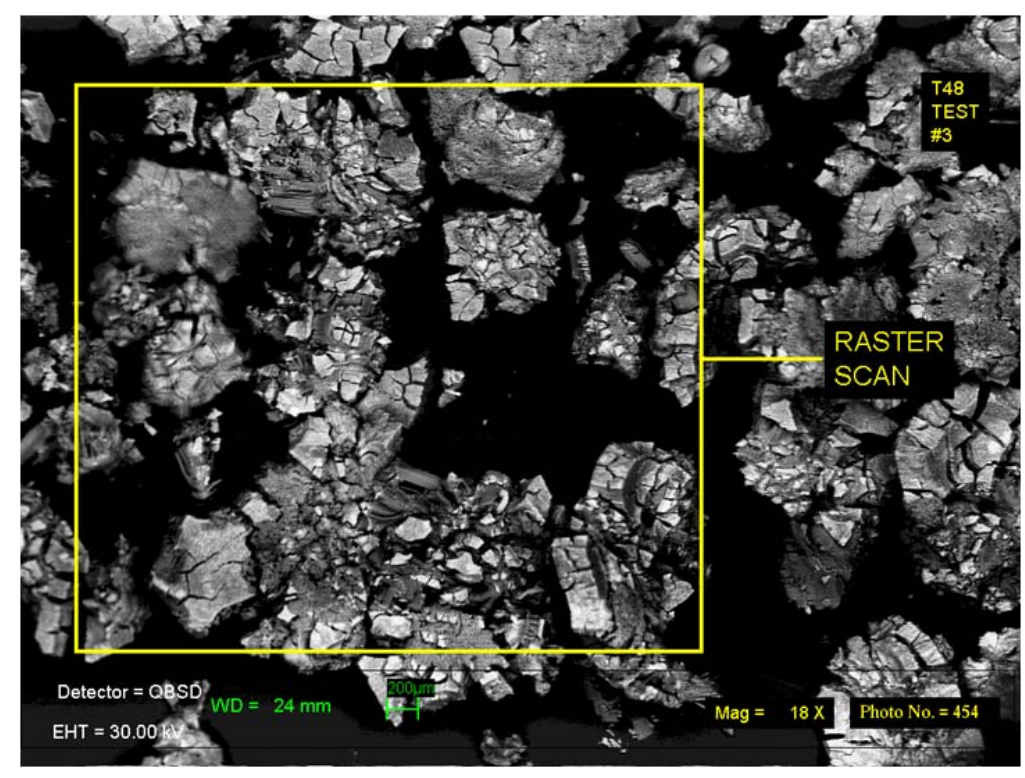

Figure A-14. SEM image of solids isolated from Test \#3.

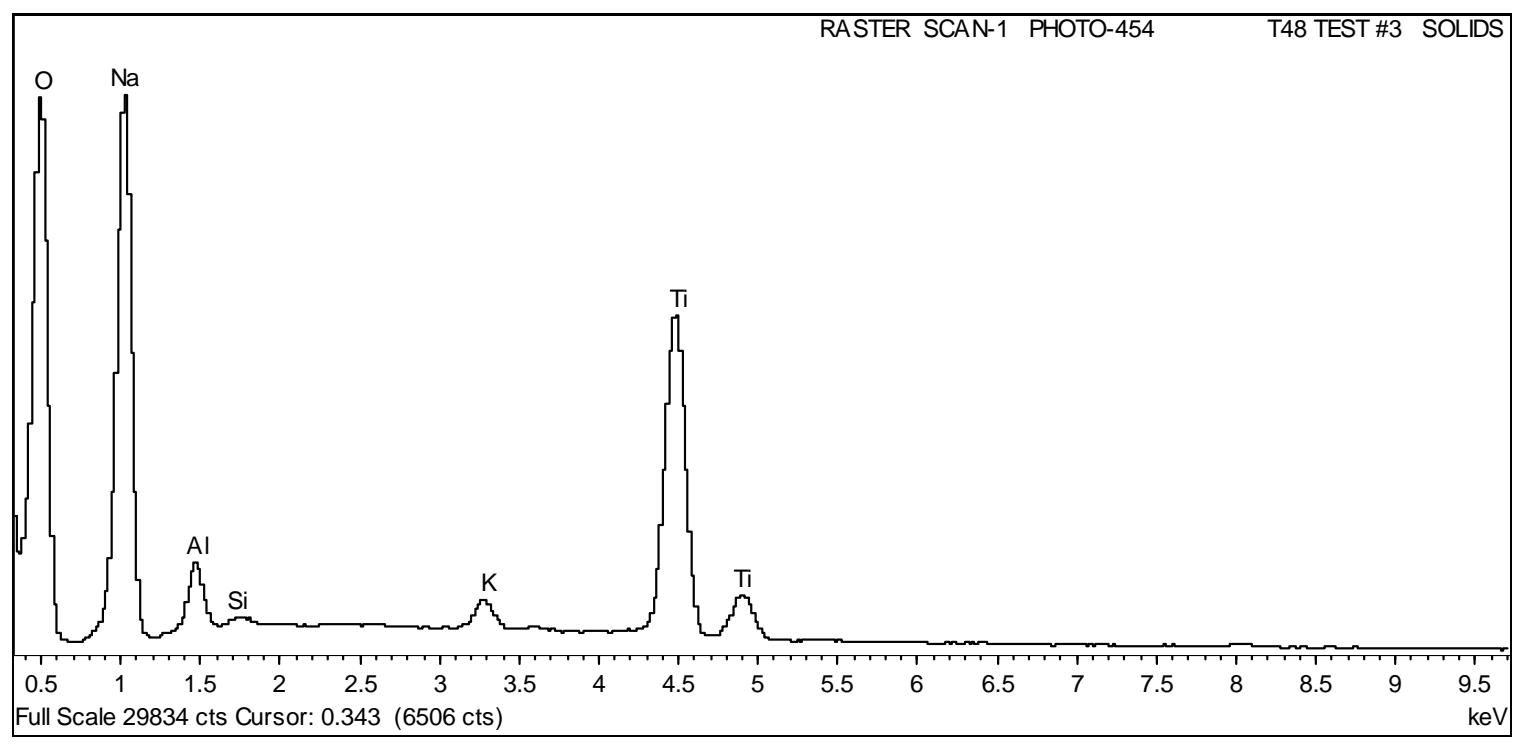

Figure A-15. EDS results from Raster Scan shown in Figure A-14. 
SRNL-STI-2012-00391

Revision 0

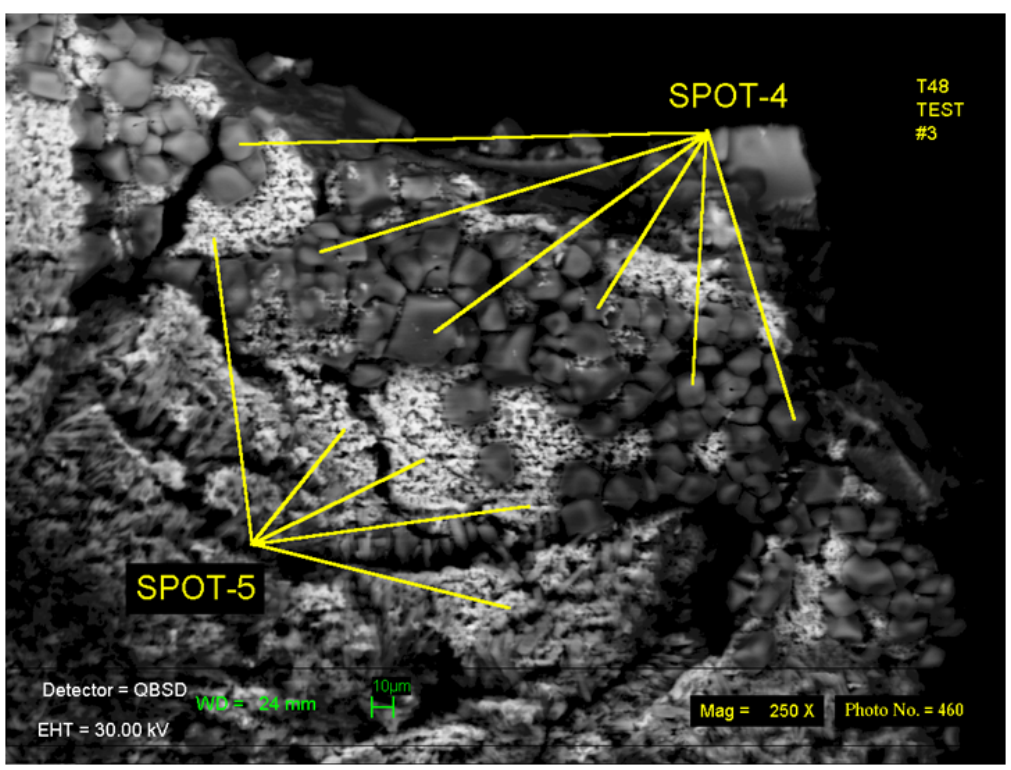

Figure A-16. SEM image of solids isolated from Test \#3.

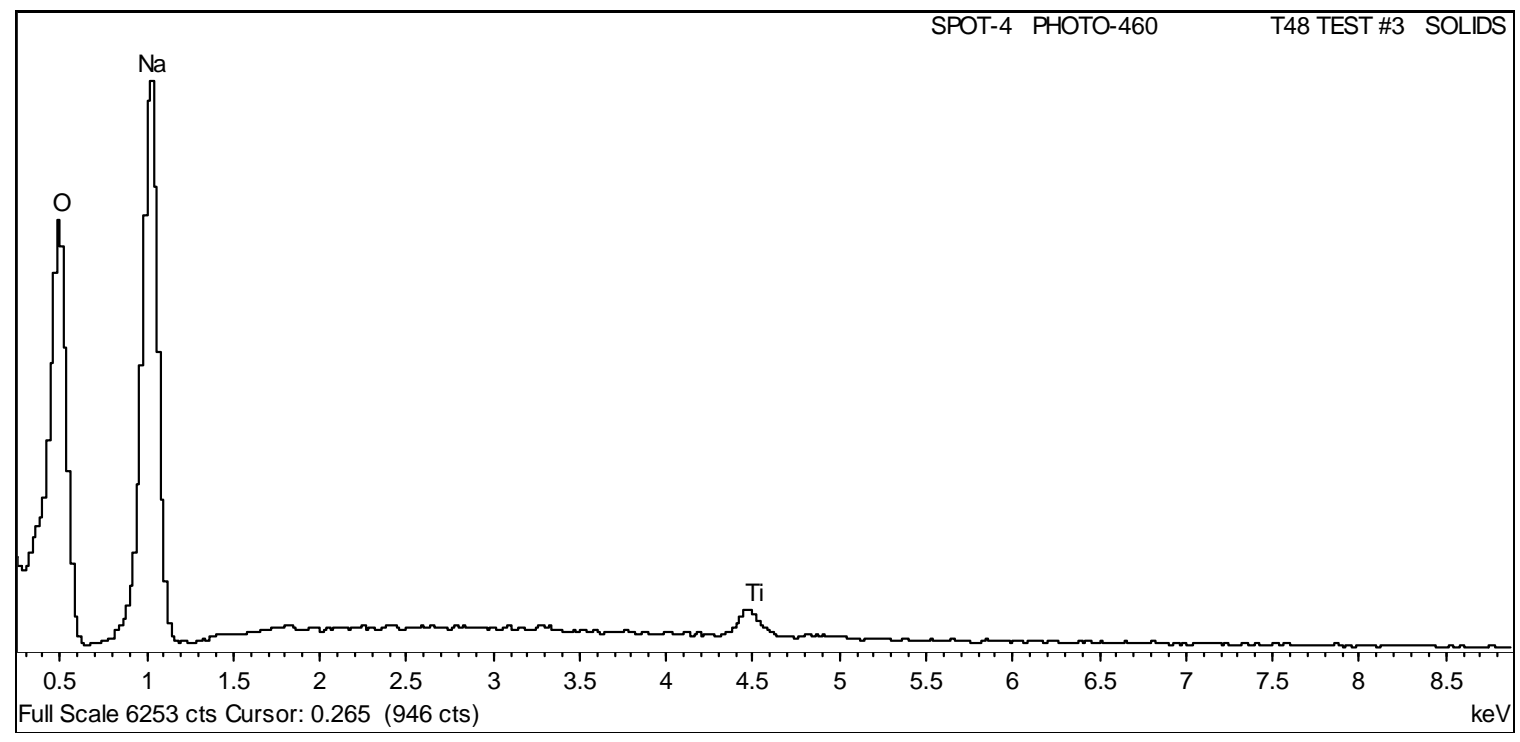

Figure A-17. EDS analysis of Spot-4 shown in Figure A-16. 
SRNL-STI-2012-00391

Revision 0

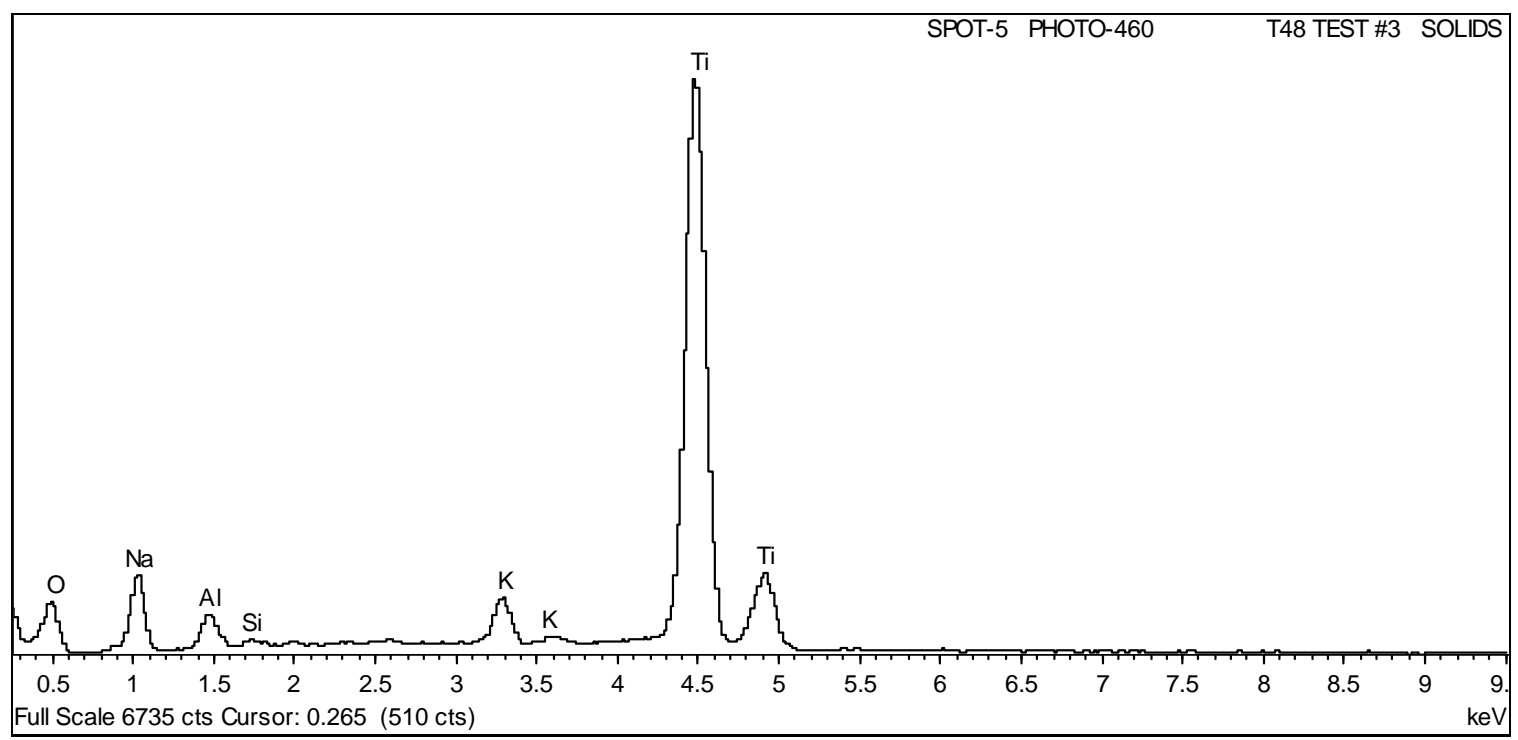

Figure A-18. EDS analysis of Spot-5 shown in Figure A-16. 


\section{Distribution:}

K. M. Fox, 999-W

S. D. Fink, 773-A

B. J. Giddings, 786-5A

C. C. Herman, 999-W

S. L. Marra, 773-A

F. M. Pennebaker, 773-42A

W. R. Wilmarth, 773-A

Records Administration (EDWS)

C. Wilson

K. M. L. Taylor-Pashow, 773-A

T. B. Peters, 773-42A

C. A. Nash, 773-42A

F. F. Fondeur, 773-A

D. T. Hobbs, 773-A

D. P. Lambert, 999-W

P. C. Suggs, 704-S

E. A. Brass, 249-8H

S. P. Simner, $249-8 \mathrm{H}$

C. I. Aponte, $249-8 \mathrm{H}$

E. J. Freed, 704-56H

D. J. Martin, 241-152H

C. E. Duffey, 704-61H

P. R. Jackson, DOE-SR, 703-46A

K. H. Subramanian, 249-8H 